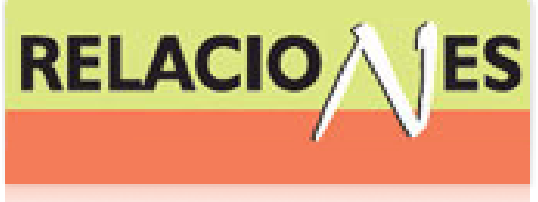

Relaciones. Estudios de historia y sociedad ISSN: 0185-3929

relacion@colmich.edu.mx

El Colegio de Michoacán, A.C

México

Riojas, Carlos

Agricultura y protoindustrialización

Relaciones. Estudios de historia y sociedad, vol. XXXIV, núm. 134, 2013, pp. 211-261

El Colegio de Michoacán, A.C

Zamora, México

Disponible en: http://www.redalyc.org/articulo.oa?id=13726972008

- Cómo citar el artículo

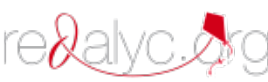

- Número completo

- Más información del artículo

Página de la revista en redalyc.org

Sistema de Información Científica

Red de Revistas Científicas de América Latina, el Caribe, España y Portugal Proyecto académico sin fines de lucro, desarrollado bajo la iniciativa de acceso abierto 
SeCción general

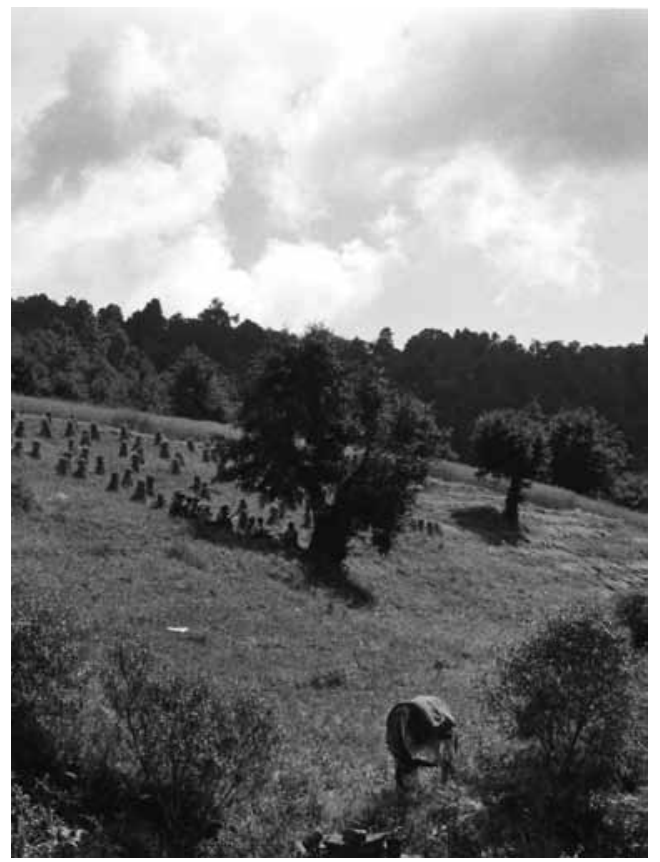





\title{
Agricultura y protoindustrialización
}

\author{
Carlos Riojas* \\ UNIVERSIDAD DE GUADALAJARA-CUCEA
}

El texto analiza las relaciones entre agricultura y protoindustrialización. La exposición se inscribe en un marco interpretativo que concibe a la industrialización como fenómeno evolutivo, donde la protoindustrialización es una etapa clave para entender el proceso en su conjunto. En primer lugar, se acota el uso del vocablo protoindustrial; luego, se aborda la organización del espacio rural; los impactos derivados del aumento en la productividad agrícola; el papel que jugó la comercialización de las actividades que se desempeñaban en el campo; cómo fue que se incrementó el trabajo no agrícola rural; y por último, la retroalimentación entre agricultura y producción manufacturera.

(Protoindustrialización, agricultura, artesanos, campesinos y manufacturas)

\section{INTRODUCCIÓN}

1 ensayo analiza, bajo una perspectiva comparada en el nivel internacional, las principales relaciones que se gestaron entre agricultura y protoindustrialización durante los siglos XVIII y XIX. La exposición se inscribe en un marco interpretativo que concibe a la industrialización como un fenómeno evolutivo de larga duración, cuya etapa inicial es clave para entender el proceso en su conjunto. Iniciamos con una acotación sobre el uso del vocablo protoindustrial. Después, abordamos la organización del espacio rural; los impactos de la productividad agrícola; el papel que tuvo la comercialización de las actividades campestres; cómo fue que se incre-

*riojas.carlos@gmail.com 
mentó el trabajo no agrícola en el medio rural; y por último, el tipo retroalimentación entre agricultura y producción manufacturera, lo que eventualmente impulsaría un crecimiento económico sin precedentes sustentado en la industrialización.

El vocablo protoindustrial se ha usado en otros estudios que abordan el funcionamiento de las pequeñas unidades de producción (PUP) ${ }^{1}$ manufactureras en diferentes zonas de la Nueva España y posteriormente México, los análisis se han concentrado básicamente entre los siglos XVIII y XIX. ${ }^{2}$ Estos estudios forman parte de

${ }^{1}$ Entendemos por pup los centros vinculados con el trabajo doméstico, taller artesanal y la red de artesanos empleados individual o colectivamente.

${ }^{2}$ Manuel Mino Grijalva, “PProto-industria colonial?”, en Historia Mexicana, 38:4, abril-junio, 1989, 793-818; H. John Coatsworth, "The economics Cycle in Bourbon Central Mexico: A Critique of the Recaudación del Diezmo Líquido en pesos, by Ouweneel and Bijleveld. II", en The Hispanic American Historical Review, 69:3, 1989, 549557; Brígida von Mentz, Trabajo, sujeción y libertad en el centro de la Nueva España. Esclavos, aprendices, campesinos y operarios manufactureros, siglos XVI a XVIII, México, Ciesas, Porrúa, 1999; Manuel Miño Grijalva, "La circulación de mercancías: una referencia al caso textil latinoamericano (1750-1810)", en Arij Ouweneel y C. Torales, coord., Empresarios, indios y Estado. Perfil de la economía mexicana (siglo XVIII), México, Universidad Iberoamericana, 1992, 75-96; Manuel Miño Grijalva, La manufactura colonial. La constitución técnica del obraje, México, El Colegio de México, 1993; Manuel Miño Grijalva, Obrajes y tejedores de Nueva España, 1700-1810, México, El Colegio de México, 1998; Arij Ouweneel, Shadows over Anáhuac. An ecological interpretation of crisis and development in central Mexico, 1730-1800, Albuquerque, New Mexico University Press, 1996; Arij Ouweneel, "The agrarian cycle as a catalyst of economic development in 18th century Central-Mexico. The arable estate, Indian village and proto-industrialization in Central highlands valleys", en Ibero-Amerikanisches Archiv, 15:3, 1989, 399-417; Arij Ouweneel, "Growth, Stagnation, and Migration: An explorative Analysis of the Tributario Series of Anahuac (1720-1800)", en The Hispanic American Historical Review, 71:3, 1991, 531-577; Carlos Riojas, Las intransitables vias del desarrollo: el proceso de industrialización en Jalisco durante el siglo XIX, México, Universidad de Guadalajara, 2003; Carlos Riojas, "Consideraciones metodológicas para el estudio del proceso de industrialización en el occidente de México durante el siglo xIx", en R. Liehr, ed., Empresas y modernización en México desde las reformas borbónicas hasta el Porfiriato, Madrid, Frankfurt, Iberoamericana, Vervuert, 2006, 130-160; Guy P.C. Thomson, "Traditional and modern manufacturing in Mexico, 1821-1850", en R. Liehr, ed., América Latina en la época de Simón Bolivar: La formación de las economías nacionales y los intereses económicos europeos 1800-1850, Berlín, Colloquim, 1989a, 62; Guy P.C. Thomson, Puebla de los Angeles. Industry and society in a Mexican City, 1700-1850, Boulder Colorado, Westwiew Press, 1989; Guy P.C. Thomson, "Continuity and Change in Mexican Manufacturing, 18001870", en J. Batou, ed., en Between development and underdevelopment: The precocious attempts at industrialization of the Periphery, 1800-1870, Ginebra, Librairie Droz, 1991, 257. 
una amplia literatura internacional que aborda el tema con un enfoque regional. De lo anterior sobresale que al menos existen tres connotaciones de protoindustrial: como adjetivo, concepto y modelo. En lo que respecta a México se ha usado básicamente como adjetivo y concepto, aunque también hay intentos de emplearlo como modelo. ${ }^{3}$ No obstante que pueda resultar fructífero utilizarlo bajo esta última acepción, sería aún más importante discutir con mayor profundidad los elementos que entrarían en juego en dicho ejercicio y, así, entender cómo éstos evolucionan a través del tiempo para relanzar la investigación sobre la industrialización en la Nueva Espańa y México. Los historiadores han señalado la interdependencia entre agricultura y protoindustrialización, ${ }^{4}$ pero una vez manifestadas dos generaciones de estudios protoindustriales es necesario replantear algunos de estos vínculos con la finalidad de reimpulsar la investigación sobre la industrialización y su impacto en la dinámica regional.

En este estudio utilizamos un corpus bibliográfico lo suficientemente representativo de la visión protoindustrial en el nivel internacional. Por lo tanto, un primer anillo concéntrico se encuentra vinculado expresamente con la protoindustrialización; mientras que un segundo, aunque no toca de forma directa la problemática del paradigma, sí incluye elementos del modelo que nos ayudan a entender el papel que tuvo la agricultura. Entonces, el hilo conductor de la exposición se da mediante los elementos de la protoindustrialización relacionados con la agricultura durante los siglos XVIII y XIX.

\section{Protoindustrialización: USOS Y CONNOTACIONES}

Un resultado de la discusión sobre las causas que desataron la Revolución Industrial ${ }^{5}$ fue la consolidación, entre los setenta y ochenta

${ }^{3}$ Carlos Riojas, "Guadalajara y sus grupos domésticos a principios del siglo xIx: una aproximación al enfoque protoindustrial”, en Jahrbuch für Geschichte Lateinamerikas, vol. 46, 2009, 313-343.

${ }^{4}$ Maxine Berg, La era de las manufacturas 1700-1820. Una nueva historia de la Revolución industrial británica, Barcelona, Crítica, 1987, 104 y 106.

${ }^{5}$ La bibliografía sobre la Revolución Industrial es amplia, sin embargo, mencionaremos sólo algunos autores emblemáticos: Karl Marx, Le Capital. Livre I, París, Quadrillage, 1993; Thomas Ashton, La revolución Industrial, 1760-1830, México, FCE, 1983; 
del siglo xx, de una visión conocida como protoindustrialización. La referencia a esta perspectiva ha sido amplia, de lo cual al menos se derivan del vocablo protoindustrial tres acepciones. Es decir, protoindustrialización se ha utilizado como adjetivo, comúnmente esta primera connotación es la más limitada y difundida cuando se abordan las etapas de la industrialización. Segundo, protoindustria o protoindustrialización se han usado como concepto dinámico o estático, según Wolfgang Mager, quien publicó su propuesta original en la revista Geschichte und Gesellschaft (1982) y retomada después. ${ }^{6}$ Esta perspectiva impactó el debate sobre la protoindustrialización en varias áreas geográficas donde se ha utilizado el concepto, e implica, una dinámica particular para diferenciar lo pre y protoindustrial.

El tercer significado de protoindustrialización es como modelo dinámico, sustentado básicamente en los estudios de Franklin Mendels $s^{7}$ y Peter Kriedte/ Hans Medick/ Jürgen Schlumbohom. ${ }^{8}$ Dicha perspectiva desató una serie de investigaciones que contribuyeron a la difusión de la protoindustrialización bajo esta acepción. Una peculiaridad de lo anterior es que se ha compuesto de varios elementos

David Landes, L'Europe technicienne ou le Prométhée libéré: Révolution technique et libre essor industriel en Europe occidentale de 1750 à nos jours, París, Gallimard, 1975; Eric Hobsbawm, Entorno a los orígenes de la Revolución Industrial, México, FCE, 1981; Fernand Braudel, Civilisation matérielle, économie et capitalisme, t. I-III, París, Folio, 1979; Maurice Dobb, Estudios sobre el desarrollo del capitalismo, México, Siglo xxI, 1988; Patrick O'Brien, "Do we have typology for the study of European industrialization in the 19th century?", en The Journal of European Economic History, 15:2, 1986, 291-333.

${ }^{6}$ Wolfgang Mager, "Proto-industrialization and proto-industry: the uses and drawbacks of two concepts", en Continuity and Change, 8:2, 1993, 181-215.

${ }^{7}$ Franklin Mendels, "Proto-industrialization: The first phase of industrialization process", en The Journal of Economic History, 32:1, 1972, 241-261; Franklin Mendels, "Social mobility and phase of industrialization", en Journal of Interdisciplinary History, 17:2, 1976, 193-216; Franklin Mendels, "Niveau des salaires et âge au mariage en Flandre, XVIIe-XVIIIe siècles", en Annales, Économies-Sociétés-Civilisations, 39:6, 1984, 939-956.

${ }^{8}$ Peter Kriedte, Hans Medick y Jürgen Schlumbohm, Industrialización antes de la industrialización, Crítica, Barcelona, 1986; Peter Kriedte, Hans Medick y Jürgen Schlumbo$\mathrm{hm}$, "Proto-industrialization revisited: demography, social structure and modern domestic industry", en Continuity and Change, 8:2, 1993, 217-252; Peter Kriedte, Hans Medick y Jürgen Schlumbohm, "Proto-industrialisation: Bilan et perspectives. Démographie, structure social et industrie à domicile modernes", en R. Leboutte, ed., Proto-industrialisation. Recherches récentes et nouvelles perspectives, Genève, Droz, 1996, 29-71. 
que al momento de deconstruir y someter sus partes a ciertas evidencias empíricas destacan las limitaciones o situaciones inexplicadas. Es precisamente esta última connotación que usaremos el resto del ensayo para exponer algunas conexiones entre agricultura y protoindustrialización. Pero, ¿cómo fue que se dio la construcción de la protoindustrialización como modelo?

En el debate sobre la Revolución Industrial se señalaron algunos factores de cambio que se incorporaron a la visión de la protoindustrialización, a saber: a) la búsqueda del excedente productivo en el medio rural estimuló la transformación de una economía ligada a la posesión territorial hacia una sustentada en la producción manufacturera, donde la economía campesina se reveló como soporte del sistema doméstico ante el permanente rechazo de los habitantes del campo a aceptar las condiciones impuestas en el sistema fabril; b) El crecimiento de la productividad agrícola desencadenó un aumento poblacional gracias a que se adelantaron la edades del matrimonio, por ende, aumentó el potencial productivo de los hogares debido al incremento de mano de obra, lo anterior se correlacionó con los precios a la baja de los productos textiles. Todos los miembros del hogar participaron temporalmente en tareas manufactureras con intensidades diversas para complementar el ingreso familiar, situación que los llevó a un lento proceso de proletarización al modificar los tiempos y ritmos de trabajo. La importancia del empleo femenino, la reorganización del hogar y el papel del aprendizaje fueron hipótesis atractivas, como también lo resultó, la inviabilidad de un sistema protoindustrial sólo sustentado en el trabajo de los adultos. Entonces, c) la aparición progresiva de grupos de trabajadores creó un contingente de mano de obra que repercutió en el aumento de la producción manufacturera en el campo. Las relaciones derivadas de ello favorecieron la expansión del comercio, en un principio sustentado en el Kaufssystem y después en el surgimiento del Verlagssystem. ${ }^{9}$

${ }^{9}$ El Kaufssystem fue una práctica sistemática mediante la cual los artesanos vendían directamente sus productos en el mercado. Mientras que en el Verlagssystem las pup eran habilitadas a través del adelanto de recursos por parte de un empresario-comerciante (Carlos Riojas, "El Verlagssystem y las estrategias empresariales", en Signos Históricos, núm. 22, julio-diciembre, 2009, 108-145). 


\section{El Verlager participó también en el financiamiento de la producción manufacturera y en mercados extrarregionales.}

Por lo tanto, con base en estas funciones se explicó la naturaleza de la industrialización. El reconocimiento y la reestructuración de dichos elementos le dio mayor impulso a la discusión. Uno de los paradigmas que mejor articuló sus respuestas a las dudas derivadas de las controversias fue la protoindustrialización, cuyas explicaciones han sido constantemente retomadas para probar su coherencia explicativa y profundizar el estudio sobre el desenlace de esta etapa. ${ }^{10} \mathrm{La}$ argumentación de la protoindustrialización, en su primera generación de estudios, fue considerar a las Pup como un actor alternativo en la industrialización, cuya estructura organizacional fue crecientemente compleja y, por lo regular, se presentó como una manifestación capaz de cohabitar con el sistema fabril, ya que hasta este momento las Pup habían sido vistas como una secuela del antiguo régimen destinadas a desaparecer.

\footnotetext{
${ }^{10}$ Ahrar Ahmad, "Analyzing pre-colonial South Asia: mode of production or protoindustrialization", en Journal of Contemporary Asia, 27:3, 1997, 318; Brian A'hearn, "Institutions, externalities, and economic growth in southern Italy: evidence from the cotton textile industry, 1861-1994”, en Economic History Review, 51:4, 1998, 754; Claude Cailly, "Contribution à la définition d'un mode de production proto-industriel", en Histore et Mesure, 7-1/2, 1993, 24; King Chao, "La production textile dans la Chine traditionnelle", en Annales ESC, 39:6, 1984, 958; Salvatore Ciriacono, "Venise et la Vénétie dans la transition vers l'industrialisation. A propos des thèses de Franklin Mendels", en R. Leboutte, ed., Proto-industrialisation. Recherches récentes et nouvelles perspectives, Ginebra, Droz, 1996, 317; Claude Desama, "Démographie et industrialisation: Le modèle verviétois (1800-1580)", en Revue du Nord, 63:248, 1981, 148; Pierre Deyon, "L'enjeu des discussions autour du concept de 'proto-industrialisation'”, en Revue du Nord, 61:240, 1979, 9; Agustín González Enciso, "La protoindustrialización en España”, en Revista de Historia Económica, 2:1, 1984, 28; Gutmann Mayron, "War and industrial development in early modern Europe", en R. Leboutte, ed., Proto-industrialisation. Recherches récentes et nouvelles perspectives, Ginebra, Droz, 1996, 154; Samuel Ho, "Protoindustrialisation, protofabriques et désindustrialisation: une analyse économique", en Annales-ESC, 39:6, 1984, 894; Paul Honenberg, "Urbanization and proto-industrialization. Reflections on an intellectual journey”, en R., Leboutte, ed., Proto-industrialisation. Recherches récentes et nouvelles perspectives, Ginebra, Droz, 1996, 9; Sheilagh Ogilvie, "Proto-industrialisation in Europe", en Continuity and Change, 8:2, 1993, 163; Pierre Jeannin, "La protoindustrialisation: développement ou impasse?", en Annales-ESC, 35:1, 1980, 52; Richard Rudolph, "Agricultural structure and proto-industrialization in Russia: economic development with unfree labor", en Journal of Economic History, 45:1, 1985, 50; Osamu Saito, "Historical Demography: achievements and prospects”, en Population Studies, 50:3, 1996, 540.
} 
A partir de lo anterior se originó un doble fenómeno. Por una parte, se evidenciaron ciertos límites de la protoindustrialización, y por otra, esta situación desembocó en el nacimiento de una segunda generación de estudios con una perspectiva más amplia y diversa. La primera generación de estudios protoindustriales tendió hacia la aplicación del modelo en su conjunto, lo que reveló una serie de inconsistencias. Mientras que la segunda generación se inclinó hacia la deconstrucción a fin de rescatar los elementos susceptibles de brindar explicaciones más coherentes, no obstante su combinación con otras herramientas y enfoques explicativos ajenos al modelo original.

$\mathrm{Al}$ igual que otros modelos, la protoindustrialización representó por sí misma una abstracción, que al ser sometida a evidencias empíricas de varios contextos mostró limitaciones. Por lo tanto, la protoindustrialización bajo esta connotación ha provocado una correspondencia incómoda entre sus principales postulados y estudios específicos que han seguido sus propuestas metodológicas. ${ }^{11} \mathrm{El}$ éxito de los modelos radica, entonces, en su capacidad para adaptarse y ofrecer interpretaciones, relativamente coherentes, ante las nuevas situaciones a las cuales se exponen. Lo anterior se logra gracias a los cuestionamientos sobre su viabilidad explicativa. Veamos algunos ejemplos.

La primera generación de estudios protoindustriales fue criticada por su sesgo hacia el medio rural. Se hablaba poco de las ciudades, así como, de las articulaciones entre zonas urbanas y entorno agrario. Esta observación se consideró en la segunda generación de estudios que trató de subsanar dicho límite. ${ }^{12}$ Es decir, se demostró que el medio rural no era el único espacio donde se manifestó la protoindustrialización, incluso, se llegó hablar de ciudades protoindustriales

${ }^{11}$ Maxine Berg, "New consumers industries in eighteenth-century England: Products, markets and metal goods in Birmingham and Sheffield", en R. Leboutte, ed., Proto-industrialisation. Recherches récentes et nouvelles perspectives, Ginebra, Droz, 1996, 213; Mary Jo Maynes, "Unthinking teleologies", en Social Science History, 30:1, 2006, 8.

${ }^{12}$ Franklin Mendels, "Le temps de l'industrie et le temps de l'agriculture. Logique d'un analyse régionale de la protro-industrialization", en Revue du Nord, 63: 248, 1981, 21; Corinne Maitte, "Incertitudes et bricolages. L'industrie textile à Prato aux 18 ème et 19ème siècle”, en Annales, HSS, 6, 1997, 1276. 
como Birmingham en el siglo XVIII, ${ }^{13}$ también se subrayó el sistema manufacturero protoindustrial establecido a finales del siglo XVIII en las regiones de Cambrésis y Saint Quentinois con sus articulaciones urbano-rurales. ${ }^{14}$ De igual forma, algunos estudios enfatizaron las relaciones entre ciudad y campo expresadas mediante las tasas de fertilidad regional, ${ }^{15}$ y la capacidad del medio rural para capitalizar las ganancias que impulsarían a la protoindustrialización como sucedió en la India en los siglos XVIII y XIx bajo el Imperio británico. ${ }^{16}$ Incluso la aparición de los pueblos-empresa en la Nueva España en el siglo XVIII reveló una fuerte articulación entre ciudad y campo, además, estimuló la industrialización en ramas vinculadas con la producción de alimentos o pequeñas fundiciones. ${ }^{17}$

Asimismo, el límite entre pre y protoindustrial generó confusiones. En este caso la protoindustrialización fue útil para explicar las diferencias con base en tiempos, relaciones, funciones y contextos históricos específicos. Pierre Deyon y Franklin Mendels intentaron dejar clara la distinción entre ambos conceptos. ${ }^{18}$ Pero resurgió la dicotomía urbano-rural, sobre todo en espacios donde había una frágil frontera. Una vez más las evidencias empíricas de la segunda generación de estudios revelaron una diversidad en las formas organizativas de esta incipiente industrialización, donde el elemento común fue la participación del núcleo familiar en la dinámica, lo que rompió de lleno con las vicisitudes del ciclo agrícola. ${ }^{19}$ Es decir, la principal distinción entre pre y protoindustrial radica en que este

${ }^{13}$ Maxine Berg, op. cit., 1987, 311 y 337.

${ }^{14}$ Didier Terrier, Les deux âges de la proto-industrie. Les tisserands du Cambrésis et du Saint-Quentinois, 1730-1880, París, EHEss, 1996, 52 y 78-79.

${ }^{15}$ George Alter, Michel Oris y Muriel Neven, "When protoindustry collapsed fertility and the demographic regime in rural eastern Belgium during the Industrial Revolution”, en Historical Social Research, 32:2, 2007, 149.

${ }^{16}$ Abhijit Banerjee y Lakshmi Iyer, "History, Institutions and Economic Performance: The Legacy of Colonial Land Tenure Systems in India”, en BREAD Working paper No. 003, Bureau for Research in Economic Analysis of Development, USA, 2003, 9.

${ }^{17}$ Von Mentz, op. cit., 1999, 284.

${ }^{18}$ Pierre Deyon y Franklin Mendels, "La proto-industrialisation: Théorie et réalité", en Revue du Nord, 63:248, 1981, 11.

${ }^{19}$ Jane Gray, "Gender composition and household labour strategies in pre-Famine Ireland", en History of the Family, 11, 2006, 4; Berg, op. cit., 1987, 34 y 44. 
último hace alusión a una serie de relaciones funcionales específicas que explican, y en su caso comprueban, el advenimiento de la industria. Mientras que en lo "pre" no existen evidencias claras sobre el inicio de la industrialización, por tanto, el ciclo agrícola es determinante en el panorama económico.

Finalmente, conforme avanzó la investigación se revelaron otros factores vinculados con la protoindustrialización. Por ejemplo, cambios en el consumo de los grupos domésticos, lo que algunos estudiosos lo interpretan como el origen de una sociedad de consumo. ${ }^{20}$ La complejidad en la composición de los hogares fue otro elemento, sobre todo, una persistente pluriactividad de los grupos domésticos en torno a la economía rural, donde influyó un conjunto de instituciones articuladas con los derechos de propiedad, el cambio técnicotecnológico y los ciclos demográficos, ${ }^{21}$ que según los criterios estrictos de la protoindustrialización, en su primera generación de estudios, ésta dejaría de funcionar. Sin embargo no fue así. Lo anterior mostraba más bien el carácter hibrido de las sociedades, como en la Nueva España durante el siglo XviıI donde se señaló un tipo de industrialización colonial vinculada de alguna forma con la protoindustrialización. ${ }^{22}$ Lo trascendente en esta discusión fue que sobresalió un sistema doméstico en transición y no un rígido modelo sin cambios trascendentes.

No obstante estas limitaciones y el replanteamiento del modelo protoindustrial, su contribución consistió en impulsar los estudios regionales en periodos históricos que abarcaban por lo general desde el siglo XVII al XIX en diferentes contextos en el nivel mundial, situación que redefinió la discusión y reveló los complejos sistemas que envuelven a la industrialización. También se consagró como una útil herramienta metodológica para entender algunas relaciones y funciones entre variables; finalmente, una vez constatadas las inherentes restricciones, surgió una segunda generación que ha incorporado en una estructura lógica nuevos elementos y críticas para proponer una

${ }^{20}$ Jan de Vries, "The industrial revolution and the industrious revolution", en Journal of Economic History, 54:2, 1994, 252; Berg, op. cit., 2004, 91.

${ }^{21}$ Oris Alter y Neven, op. cit., 2007, 149; Berg, op. cit., 1987, 100.

${ }^{22}$ Von Mentz, op. cit., 1999, 238. 
interpretación más amplia. ${ }^{23}$ Esta última generación de estudios fue menos prolífica en cuanto al número de publicaciones, pero presentó mayor rigor metodológico en un área tradicionalmente compleja para el análisis de la industrialización. Su principal resultado consistió en demostrar los límites de la protoindustrialización, sobre todo, cuando se construía sólo con base en eventos vinculados a la producción textil. El estudio de otras actividades manufactureras, la aparición de nuevos productos, las repercusiones del conocimiento y el aprendizaje, las relaciones culturales en contextos de transformación demográfica, así como, la coexistencia con múltiples estructuras socioeconómicas a través del tiempo y espacio resultaron cruciales. ${ }^{24} \mathrm{~A}$ pesar de todo, la protoindustrialización ha mantenido su potencial explicativo de carácter global, del cual se pueden extraer elementos útiles para guiar la investigación.

\section{LA ORGANIZACIÓN DEL ESPACIO RURAL}

Una diferencia entre las áreas pre y protoindustriales radicó en la organización del espacio rural, lo que sirvió para aumentar la productividad agrícola a través del tiempo y permitió un crecimiento económico sin precedentes gracias a una disposición adicional de recursos. ${ }^{25}$ El auge de la agricultura comercial contribuyó a la expansión de mercados. Paralelamente, se gestaron otros fenómenos como la permanencia de tareas tradicionales que habían logrado

${ }^{23}$ Maxine Berg, "The genesis of 'useful knowledge", en History of Science, 45:2, 2007, 127; Pat Hudson y Steve King, "Two textile townships, c. 1660-1820: A comparative demographic analysis", en The Economic History Review, 53:4, 2000, 715; Steven A. King, "The English proto-industrial family: old and new perspectives", en History of the Family, 8:1, 2003, 38.

${ }^{24}$ Maxine Berg, "In pursuit of luxury: global history and British consumer goods in the eighteenth century", en Past and Present, 182, 2004, 85-141; Francois M.M. Hendric$\mathrm{kx}$, "Family, farm, and factory: Labor and the family in the transition from protoindustry to factory in $19^{\text {th }}$ century Twente, The Netherlands", en History of the Family, 8:1, 2003, 53; Sheilagh Ogilve y Jeremy Edwards, "Women and the 'Second Serfdom': Evidence from Early Modern Bohemia”, en The Journal of Economic History, 60:4, 2000, 979.

${ }^{25}$ Paul Bairoch, "La agricultura y la Revolución Industrial 1700-1914", en Carlo Cipolla, coord., Historia económica de Europa. La Revolución Industrial, Barcelona, Ariel, 1983, 496. 
consolidarse en el medio rural. También, se detectó un conjunto de actividades no tradicionales, lo que implicó la expansión de oportunidades productivas.

La permanencia de las actividades tradicionales estuvo en función de sus capacidades para coexistir con otras tareas alternativas en el campo, como las manufacturas. El denominador común de lo anterior fueron las articulaciones entre la economía familiar y los factores regionales, lo que contribuyó para consolidar las actividades tradicionales. Existen esquemas interpretativos y niveles de aportación teórica que sustentan diversas perspectivas basadas en la compleja articulación campo-ciudad, las cuales enfatizan el permanente temor de una crisis de subsistencia; ${ }^{26}$ las limitaciones ecológicas del espacio ${ }^{27}$ vinculaciones típicas de un régimen de producción feudal, ${ }^{28} \mathrm{o}$ la influencia de factores institucionales y culturales. ${ }^{29}$ Independientemente de ello, estos espacios alcanzaron un grado de desenvolvimiento económico que les permitió solventar los obstáculos inherentes al crecimiento de la agricultura, im-

${ }^{26}$ D.C. Coleman, "Proto-industrialization: a concept too many", en The Economic History Review, 36:3, 1983, 436; Patrick O’Brien, "Path Dependency or Why Britain Became an Industrialized and Urbanized Economy Long before France", en The Economic History Review, 49:2, 1996, 242; Irma Adelman y Cynthia Taft Morris, "The Role of institutional influence in patterns of agricultural development in the nineteenth and early twentieth centuries: a cross-section quantitative study", en Journal of Economic History, 39:1, 1979, 164.

${ }^{27}$ Alejandro Tortolero Villaseñor, Notarios y agricultores. Crecimiento y atraso en el campo mexicano, 1780-1920. Propiedad, crédito, irrigación y conflictos sociales en el agro mexicano, México, UAm Iztapalapa, Siglo XXI, 2008, 33.

${ }^{28}$ José Carlos Chiaramonte, Formas de sociedad y economía en Hispanoamérica, México, Grijalbo, unAm, 1984, 227; Edgar Melton, "Proto-industrialization, Serf Agriculture and Agrarian Social Structure: Two Estates in Nineteenth-Century Russia”, en Past and Present, 115, 1987, 69; Liliana Vardi, "Imagining the harvest in early Modern Europe", en The American Historical Review, 101:5, 1996, 1357.

${ }^{29}$ Marcelo Carmagnani, "Demografía y sociedad: La estructura social de los centros mineros del norte de México, 1600-1720”, en Historia y población en México. Lecturas de Historia Mexicana 9, México, El Colegio de México, 1994, 123; Arij Ouweneel, “The agrarian cycle as a catalyst of economic development in 18th century Central-Mexico. The arable estate, Indian village and proto-industrialization in Central highlands valleys", en Ibero-Amerikanisches Archiv, 15:3, 1989a, 402; Karen Wigen, "The geographic imagination in early modern Japanese history: Retrospect and prospect", en Journal of Asian Studies, 51:1, 1992, 4; François Weil, "Capitalism and industrialization in New England, 1815-1845”, en The Journal of American History, 84: 4, 1998, 1342. 
pulsar una diferenciación geográfica, ir más allá del medio rural y transformar sus principales rasgos sin desvincularse de las actividades tradicionales.

En el proceso de consolidación de dichas actividades permanecieron elementos tales como el arraigo en el tipo de cultivo, los determinantes geográficos que favorecieron la especialización local o la articulación entre espacios y expresiones culturales que giraban en torno a la economía. Con base en ello, se impulsaron cambios en las prácticas agropecuarias que impactaron al sistema productivo en su conjunto. ${ }^{30} \mathrm{La}$ clave de dichas manifestaciones radicó en que las actividades tradicionales encontraron modos de funcionamiento que les permitieron compartir un espacio específico con otras tareas que paulatinamente modificaban el panorama rural, como lo fue la aparición de las manufacturas. ${ }^{31}$ Por ejemplo, en una zona que va desde El Bajío hasta las inmediaciones de Guadalajara fue palpable, en el siglo XVIII, cómo la ganadería, la siembra de granos y las manufacturas locales se reprodujeron gracias a las complementariedades que de ellas se derivaban, lejos de sustituirse las unas por las otras, se articularon para originar una de las áreas más dinámicas en la época colonial tardía, mientras que en el centro de México, ya en el siglo XIX, cohabitaron una agricultura de autoconsumo vinculada a los pueblos, minifundios o pequeñas propiedades, con una agricultura comercial impulsada por las plantaciones de las haciendas y los prósperos ranchos. ${ }^{32}$

Por otra parte, existieron casos donde se clarifica la influencia de instituciones en la permanencia de actividades tradicionales. Era frecuente que los productos agrícolas y artesanales en el siglo XvIII en la India se intercambiaran sin tomar en cuenta las reglas del mer-

${ }^{30}$ Carlo M. Cipolla, Historia económica de la población mundial, México, Grijalbo, Conaculta, 1990, 21; Alfred W. Crosby, Ecological imperialism. The biological expansion of Europe, 900-1900, Nueva York, Canto, 1999, 18; Alain Dewerpe, L'Industrie aux Champs, essai sur la protoindustrialisation en Italie du Nord (1800-1880), París, Roma, Collection de l'École Française de Rome-Palais Farnèse, 1985, 7.

${ }^{31}$ David L. Howell, "Proto-industrial origins of Japanese capitalism", en Journal of Asian Studies, 51:2, 1992, 276; O'Brien, op. cit., 1996, 224.

${ }^{32}$ Manuel Miño, op. cit., 1992, 78; Alejandro Tortolero, op. cit., 2008, 38. 
cado; en estas transacciones intervenían el tipo de matrimonio, el clientelismo o las creencias religiosas. ${ }^{33}$ Mientras que los respectivos sistemas sociales en China y Japón, con una fuerte jerarquía, impactaron las relaciones económicas, especialmente aquellas vinculadas con la agricultura de subsistencia y comercial. ${ }^{34}$ De igual forma, en Europa las estructuras institucionales tuvieron un papel importante, donde destacaron las conductas demográficas que daban como resultado la composición del grupo doméstico, también se agregaron la densidad poblacional, el acceso a los recursos naturales y las modalidades para transmitir las herencias. ${ }^{35} \mathrm{~A}$ la lista se suman los aspectos políticos, cruciales en Norteamérica, que desencadenaron las fuerzas económicas tendientes a impulsar decisivamente las actividades tradicionales y de paso la industrialización en el siglo XVIII. ${ }^{36}$ Por lo que corresponde a México, comúnmente a la hacienda se le había visto como un factor negativo en cuanto al desempeño agrario dada su aparente imagen monolítica; pero, investigaciones más detalladas al respecto han demostrado cómo en esta unidad de producción se gestaron relaciones sociales en una geografía variable, que no necesariamente respondían exclusivamente a indicadores económicos, lo anterior sirvió para incentivar la permanencia de actividades tradicionales y la coexistencia con otras formas productivas que compartían el mismo lugar económico y en ocasiones visiones culturales semejantes como parte de un fenómeno sofisticado con manifestaciones múltiples desde el punto de vista socioespacial. ${ }^{37} \mathrm{El}$ arraigo de factores institucionales en el campo ha sido una característica en el mundo rural hispanoamericano, donde sobresa-

${ }^{33}$ C.A. Bayly, "State and economy in India over seven hundred years", en The Economic History Review, 38:4, 1985, 596.

${ }^{34}$ Marie-Claire Bergere, "On the historical origins of Chinese underdevelopment", en Theory and Society, 13, 1984, 332; Howell, op. cit., 1992, 280.

${ }^{35}$ Robert S. Duplessis, "Sheilagh Ogilvie, State corporatism and proto industry: the Wurttember black forest 1580-1797, Nueva York, Cambridge University Press, 1997”, en Canadian Journal of History/Annales canadiennes d'histoire, 33, 1998, p.290; Coleman, op. cit., 1983, 442; Aldeman y Taft, op. cit., 1979, 175.

${ }^{36}$ Weil, op. cit., 1998, 1343.

${ }^{37}$ Eric van Young, "The New Cultural History Comes to Old Mexico", en The Hispanic American History Review, 79:2, 1999, 214; Alejandro Tortolero, op. cit., 2008, 7; Ouweneel, op. cit., 1989'a 389. 
len los elementos políticos y jurídicos para preservar las propiedades, la posesión y el disfrute de riquezas, sin que lo anterior se interprete como el funcionamiento de un modo de producción específico. Más bien se trató de peculiaridades que permanecieron en el entorno agrario lo que permitió encontrar largos periodos de continuidad para las actividades tradicionales.

La organización del espacio también impulsó las actividades no tradicionales en el entorno agrario, situación que implicó la expansión de oportunidades productivas y la disposición adicional de recursos. Dicha transformación definió con mayor precisión algunas zonas especializadas en la agricultura comercial con respecto a los espacios donde proliferó la producción manufacturera rural. ${ }^{38}$ Pero en otros casos estas manifestaciones se conjugaron en un mismo lugar, lo cual aumentó el número de elementos que intervinieron en la industrialización. En ambas experiencias se registró el desequilibrio inherente al crecimiento económico, ${ }^{39}$ donde algunas actividades como las manufacturas crecieron más rápido que otras, cuyo resultado fue la conducción de la economía regional hacia una transformación sustentada en una base protoindustrial.

Estos cambios se originaron de las iniciativas de actores económicos relacionados directamente con la producción y de las acciones de las respectivas autoridades. En lo que concierne al primer caso, desde al siglo XVII hasta el siglo XIX se presentó una amplia variedad de formas de industrialización en Europa, Asia y América en el ámbito urbano y rural. Una peculiaridad de ello fue la articulación entre dichos entornos, donde la producción doméstica jugó un papel destacado. De igual forma, se revelaron estrategias que respondían a las fluctuaciones temporales de las actividades agrícolas, a los sistemas agrarios con una fuerte presión derivada del incremento poblacional, a una creciente complejidad en la división del trabajo con una mano de obra calificada y al factor de proximidad geográfica de los mercados

${ }^{38}$ González, op. cit., 1984, 13.

${ }^{39}$ Robert M. Solow, La teoría del crecimiento, México, FCE, 1992, 23; Hagan Koo, "From farm to factory: proletarianization in Korea", en American Sociological Review, $55: 5,1990,672$. 
vinculados con redes de transporte. ${ }^{40}$ Incluso, en el caso de Minas Gerais, ${ }^{41}$ la minería también impactó el ritmo y expansión de las manufacturas. Sin embargo, dentro de esta geografía polivalente de la industrialización, en algunos contextos agrarios el brote de la producción manufacturera se presentó aun donde se había registrado una próspera actividad agrícola, y no siempre se evidenció de manera inequívoca en zonas deprimidas, fueron los casos de Japón ${ }^{42}$ y la región central de Nueva España durante el siglo XviII. ${ }^{43}$

Por lo que respecta a la influencia de las autoridades, sobresalió la participación de la realeza checa durante el siglo XviII, cuando fomentaron las manufacturas en áreas rurales con el objetivo de enfrentar la escasez de alimentos, no obstante los desafíos tecnológicos que dicha situación representaba. ${ }^{44}$ El Estado colonial en la India estimuló la articulación de la economía agraria con otras actividades para hacer más dinámico el crecimiento económico. ${ }^{45}$ También, las tareas afines a la promoción significaban, entre otras cosas, la articulación de actividades tradicionales y no tradicionales. Un ejemplo lo encontramos en el molino de agua en Europa, Asia y América, que amplió sus usos conforme avanzó la complejidad del sistema productivo, lo cual le dio una amplia flexibilidad para impulsar la industrialización y el crecimiento económico. ${ }^{46}$

Las actividades no tradicionales en el campo expandieron las posibilidades productivas gracias a su articulación con la economía local, participación en mercados extrarregionales, contribución del

${ }^{40}$ R. A. Butlin, "Early industrialization in Europe: concepts and problems”, en Geographical Journal, 152:1, 1986, 6; Rudolph, op. cit., 1985, 49.

${ }^{41}$ Douglas C. Libby, "Reconsidering Textile Production in Late Colonial Brazil: New Evidence from Minas Gerais", en Latin American Research Review, 1:1, 1997, 91.

${ }^{42}$ Howell, op. cit., 1992, 276.

${ }^{43}$ Ouweneel, "Raíces del chiaroscuro en México algunas consideraciones acerca de esta compilación”, en Arij Ouweneel y C. Torales Pacheco, coord., Empresarios, indios y Estado. Perfil de la economía mexicana (siglo XVIII), México, Universidad Iberoamericana, 1992a, 29; Coatsworth, op. cit., p. 90.

${ }^{44} \mathrm{John} \mathrm{H}$. Komlos, "Poverty and industrialization at the end of the 'Phase-transition', en Czech Crown Lands”, en Journal of Economic History, 43: 1, 1983, 130.

${ }^{45}$ Rajnarayan Chandavarkar, "Industrialization in India before 1947: Conventional Approaches and Alternative Perspectives", en Modern Asian Studies, 19:3, 1985, 635.

${ }^{46}$ Cipolla, op. cit., 1990, 52; Wigen, op. cit., 1992, 14; Weil, op. cit., 1998, 1335. 
sector agrario mediante el tipo de tecnología y mano de obra empleadas, así como, la especialización en los cultivos. Este conjunto de transformaciones ha sido señalado por eminentes historiadores como un prerrequisito clave para el surgimiento de la era industrial. ${ }^{47}$

Un elemento central en la expansión de oportunidades fue el papel jugado por el trabajo a domicilio disperso en el campo, gracias a un periodo relativamente largo de crecimiento económico. ${ }^{48}$ Aunque la introducción de las fibras y los tejidos tienen una historia que se origina desde la antigüedad, ${ }^{49}$ aquí lo destacado fue la combinación de factores que permitió la aparición y consolidación de nuevas tareas productivas asociadas directamente con la organización productiva del espacio y el incremento de opciones económicas. En el caso de España durante el siglo xviıI, la dispersión del trabajo a domicilio logró la especialización productiva en lana, seda, algodón y lino. Por lo que corresponde a Cataluña, la inserción de su economía rural en un dinámico sistema de intercambios le permitió indagar más allá de su ámbito regional. ${ }^{50}$ Un elemento común en esta gama de manifestaciones fue la reorganización del espacio rural con base en la disponibilidad de recursos. Como el caso de Nueva Inglaterra en el siglo xIx donde el agua jugó un papel clave como proveedora de energía para las manufacturas, situación que motivó a los capitalistas locales a financiar los textiles de algodón, lo que a su vez dio nacimiento a proyectos vinculados con la energía hídrica bajo la sombra de la Compañía Manufacturera de Boston y Springfield, así como la mejora de los transportes. Eventos que desencadenaron un proceso de retroalimentación entre diversas compañías. ${ }^{51}$

${ }^{47}$ François Cochet y Gérard Henry, Les Révolutions Industrielles: processus historique, développements économiques, París, Armand Colin, 1995, 16; Albert Feuerwerker, "Presidential address: questions about china's early modern economic history that I wish I could answer", en Journal of Asian Studies, 51:4, 1992, 758; Medick Kriedte y Schlumbohm, op. cit., 1986, 63; Bairoch, op. cit., 1983, 464.

${ }^{48}$ Lloyd G. Reynolds, "The Spread of Economic Growth to the Third World: 18501980", en Journal of Economic Literature, 21:3, 1983, 943.

${ }^{49}$ Joy McCorriston, "The fiber revolution: textile extensification, alienation, and social stratification in ancient Mesopotamia", en Current Anthropology, 38:4, 1997, 518.

${ }^{50}$ Jaume Torras Elias, "Especialización agrícola e industria rural en Cataluña en el siglo xvıII", en Revista de Historia Económica, 2:3, 1984, 118; González, op. cit., 1984, 23.

${ }^{51}$ Weil, op. cit., 1998, 1334. 
El surgimiento de actividades no tradicionales en el campo descansó en la disposición adicional de recursos, que sirvió de apoyo para indagar en tareas no agrícolas y mostrar la capacidad de materializar las nuevas oportunidades económicas. El incremento de los miembros en los grupos domésticos vinculados con la agricultura en Europa durante los siglos XVII y XVIII fue una de las causas que derivó en el aumento de la complejidad en la composición de dichos grupos y en el creciente número de personas con derecho a trabajar la tierra pero sin poseerla. Lo anterior es un factor clave para entender la disposición adicional de recursos en un mundo dominado por la producción doméstica y el incentivo de utilizar éstos en tareas manufactureras en el medio rural, situación que desembocó en la coexistencia de diversos sistemas conectados con la economía local. La evolución técnica fue otra de las causas que jugó a favor de esta misma dinámica. ${ }^{52}$

Por lo que respecta a las nuevas oportunidades económicas, como lo fueron las manufacturas, éstas sirvieron para reducir la vulnerabilidad derivada de largos inviernos y el subsecuente aumento de precios en los alimentos. Este hecho se presentó especialmente en espacios donde las actividades agrícolas tenían una productividad baja, una propensión relativamente fácil para la penetración del capital comercial y una participación en un esquema de complementariedad con otras regiones que poseían mayor potencial agrícola. ${ }^{53}$ Dichas características contribuyeron a redefinir la organización del espacio rural susceptible de impulsar un sistema productivo de tipo protoindustrial, tal y como sucedió en Francia durante el siglo XIX. ${ }^{54}$ Sin embargo, el caso de Galicia en España resulta hasta cierto punto paradójico de acuerdo a lo relatado por Agustín González, quien señala la presencia de una especialización gallega en la lencería, la cual se abastecía de materias primas de León y Castilla, mientras que vendía su producción en este último lugar y en ocasiones en el País

52 David Kertzer, "Household History and Sociological Theory", en Annual Review of Sociology, 17, 1991, 166.

${ }^{53}$ Komlos, op. cit., 1983, 129.

${ }^{54}$ Gay L. Gullicson, "Agriculture and cottage industry: redefining the cause of proto-industrialization", en Journal of Economic History, 43:4, 1983, 835. 
Vasco; a pesar de ello, González considera que lo anterior no es motivo para hablar de un putting-out system dado que no se logró una especialización importante, una visible división del trabajo y una significativa incursión del capital mercantil. ${ }^{55}$ Aún así, fue notable la reorganización del espacio gracias a recursos adicionales que sirvieron para impulsar las manufacturas.

\section{LA PRODUCTIVIDAD AGRÍCOLA}

La búsqueda del permanente aumento de la productividad agrícola se sustentó en la organización del espacio rural, estrategia inherente a las áreas protoindustriales. En esta lógica, algunas sociedades cumplieron dos requisitos básicos para impulsar la industrialización: dispusieron de los alimentos necesarios que demandaba la creciente población urbana y produjeron las materias primas requeridas por las empresas involucradas en elaborar manufacturas. A partir de ello, algunos especialistas se concentraron en analizar el lento proceso de transformación estructural que dio origen al aumento continuo de la productividad agrícola, el cual se manifestó mediante el crecimiento en la cantidad per cápita de alimentos, el incremento de excedentes, la acumulación de microinvenciones y los cambios institucionales, especialmente aquellos vinculados con los derechos propiedad. ${ }^{56} \mathrm{De}$ esta forma, se impulsaron nuevas relaciones en el campo y se prepararon las condiciones para estimular la industrialización. Algunas áreas de observación que han servido para sustentar estas manifestaciones fueron Europa durante los siglos XvII y xvIII, el norte de China y en menor medida el valle de México en el siglo XVIII. ${ }^{57}$ En todos los casos, fueron claras las habilidades que desarrollaron los humanos para controlar y aumentar la producción de alimentos.

Un análisis más detallado de las regiones donde se generó este fenómeno pone en relieve las áreas de subsistencia, donde la presión

${ }^{55}$ González, op. cit., 1984, 22.

${ }^{56}$ Bairoch, 1983, op. cit., 465; Adelman y Taft, op. cit., 1979, 173.

${ }^{57}$ E.A. Wrigley, Gentes, ciudades y riqueza. La transformación de la sociedad tradicional, Barcelona, Crítica, 1992, 24, 29 y 47; Ouweneel, op. cit., 1992a , 23; Cochet y Gérard, op. cit., 1995, 72 y 82; Cipolla, op. cit., 1990, 22 y 45. 
demográfica y ecológica jugaron un papel importante para el surgimiento de la producción manufacturera. Además, estos espacios se articularon con otros territorios que practicaron una agricultura comercial basada en el aumento de la productividad. ${ }^{58}$ Situación que impulsó la especialización regional, fortaleció los niveles de nutrición, incrementó las medidas de higiene y redujo las posibilidades de contraer enfermedades. ${ }^{59} \mathrm{Si}$ las zonas que tenían un precaria producción agrícola no estaban inmersas en un subsistema regional, que les permitiera obtener los recursos necesarios para solventar las actividades cotidianas, era factible que en ellas brotara la hambruna. Resulta interesante señalar que ambas manifestaciones se dieron en el Valle de México durante el siglo xviII como parte de las tendencias cíclicas inherentes a la agricultura. ${ }^{60}$

Gracias a una disposición adicional de recursos la productividad agrícola se incrementó constantemente, lo cual se reflejó en un crecimiento económico sin precedentes. Lo anterior se manifestó en un contexto cambiante, donde destacaron la decreciente dependencia alimentaria de origen vegetal, el incremento en el consumo de proteínas, la tendencia hacia la baja en los precios relativos de los granos, una composición dietética más balanceada, la consolidación de actividades transformadoras de materias primas, el uso más intensivo de la tierra cultivada, así como, el mayor número de animales criados por metro cuadrado gracias a la introducción de especies menores. ${ }^{61}$

La creciente modernización de la agricultura comercial, entendida como la introducción sistemática de cambios técnico-tecnológicos para incrementar la productividad y por ende el producto final, contribuyó a la expansión de los mercados, que dependían en gran medida de las regiones con un alto grado de urbanización. ${ }^{62}$ En algunos lugares, como fue el caso de la Nueva España a finales del si-

${ }^{58}$ Kriedte, Medick y Schulumbohm, op. cit., 1986, 49;

${ }^{59}$ Reynolds, op. cit., 1983, 951.

${ }^{60}$ Ouweneel, op. cit., 1991, 560; Ouweneel, op. cit., 1992a , 13, 15 y 17.

${ }^{61}$ Domar, Evsey y Machina, Mark, "On the profitability of Russian Serfdom", en The Journal of Economic History, 44:4, 1984, 920; Cipolla, op. cit., 1990, 42.

${ }^{62}$ Kriedte, Medick y Schlumbohm, op. cit., 1986, 48; Vardi, op. cit., 1996, 1361. 
glo XVIII, existieron grandes extensiones territoriales que eran dedicadas al pastoreo y a la siembra. La intensidad en el uso de estas tierras estaba en función de la demanda de los centros poblacionales. Cuando esta última era débil, no se generaban los incentivos necesarios para promover la diversidad de productores, tampoco para incrementar la oferta de alimentos. Fenómeno que en ocasiones se acompańó con movimientos migratorios lo que dio origen a un círculo vicioso. ${ }^{63}$ En un escenario como el anterior, el mercado tuvo un papel importante como estimulador de la producción agrícola y de las actividades que se organizaban en el campo. Hechos que ratifican las complejas relaciones que mantuvieron la agricultura y producción manufacturera a través del tiempo.

\section{LA COMERCIALIZACIÓN EN EL CAMPO}

Cuando la comercialización y el incremento de la productividad agrícola surgieron en un ambiente caracterizado por el aumento demográfico se abrió la posibilidad para los campesinos-artesanos de indagar en la producción manufacturera. ${ }^{64}$ Entonces, las variables asociadas al comercio tomaron mayor trascendencia en el sistema económico, lo que desembocó en un panorama crecientemente complejo en torno a las conductas demográficas y al tejido productivo local. Según los estudiosos de las transformaciones económicas en Inglaterra existieron tres variables clave que impulsaron su industrialización y crecimiento económico, a saber: el comercio exterior, la dinámica demográfica y los niveles de las cosechas. ${ }^{65}$ Las dos últimas se relacionaron con factores endógenos, mientras que la primera, a pesar de su vinculación exógena, dependió en gran medida de la dinámica demográfica y de las cosechas.

Por lo regular, la agricultura comercial se practicaba en zonas donde el acceso a los mercados urbanos era relativamente fácil. ${ }^{66} \mathrm{La}$

${ }^{63}$ Arnold Bauer, "Las estructuras agrarias en la América Española”, Historia General de América Latina, vol. vi, París, unesco, Trotta, 2003, 296.

${ }^{64}$ Desama 1981, op. cit., p. 152; Kriedte, Medick y Schlumbohm, op. cit., 1996, 32.

${ }^{65}$ Cochet y Henry, op. cit., 1995, 212.

${ }^{66}$ Gullicson, op. cit., 1983, 840; Adelman y Taft, op. cit., 1979, 166. 
articulación entre producción agrícola, estructura de la propiedad y de población fue clave para el crecimiento económico, debido a que la relación positiva entre el incremento de los habitantes y la cantidad de recursos disponibles tuvo el potencial de estimular las manufacturas y dinamizar el sistema en su conjunto. En contraparte, cuando se presentó un desequilibrio entre ellos o una escasez de recursos, que no fuese posible subsanar en el corto plazo mediante la complementariedad regional, era común que se generaran problemas de crecimiento y distorsiones económicas, dada la incapacidad para abastecer los alimentos necesarios que sustentarían el aumento demográfico. El desarrollo de la agricultura comercial resolvió gradualmente este conflicto. ${ }^{67}$ Un ejemplo de ello, lo encontramos en el valle central de Chile durante el siglo XIX, que debido a su clima y cercanía con la ciudad de Santiago, predominó una zona agrícola productora de alimentos esencialmente para consumo interno. Algo similar ocurrió en Venezuela, Puerto Rico y Santo Domingo. ${ }^{68}$

Entonces, el principal vínculo entre la agricultura comercial y dinámica poblacional se dio mediante la reorganización productiva, gracias a la constante demanda de alimentos e incremento de la fuerza laboral susceptible de emplearse en el campo y producción manufacturera. De especial importancia fue el lugar que ocuparon las mujeres en las relaciones productivas, tal y como se evidenció en la región de Pays de Caux durante el siglo XviII, donde se percibió con mayor nitidez la tradicional división del trabajo femenino en el hilado y tejido domésticos. ${ }^{69}$ Asimismo, la presión demográfica y la persistente influencia del mercado forzaron a algunas empresas en el campo a reestructurar sus procesos productivos mediante el cambio técnico-tecnológico para atender una creciente demanda. Lo anterior fue evidente a finales del siglo XVIII y gran parte del siglo XIX en las haciendas y los ranchos mexicanos, especialmente en aquellas unidades productivas cercanas a las principales ciudades que experi-

${ }^{67}$ Ouweneel, op. cit., 1992a, 26; Bairoch, op. cit., 1983, 472.

${ }^{68}$ David Bushnell, "Estructura social y espacio geográfico”, en Carrera D. Germán y John Lombardi, coords., La crisis estructural de las sociedades implantadas. Historia General de América Latina, vol. v, París, unesco, Trotta, 2003, 123 y 130.

${ }^{69}$ Gullicson, op. cit., 1983, 844. 
mentaban un proceso de crecimiento demo-urbano con las respectivas transformaciones de sus Hinterland. Pero, al ver estos elementos agregados y bajo una perspectiva de largo plazo para el caso de México, tenemos que se revelaron límites que han puesto en duda la capacidad de estas articulaciones para generar crecimiento económico sostenido. Entre ellos destacaron la inexistencia de un mercado de trabajo libre que sustentara dicha dinámica, un raquítico sistema de crédito que dio la pauta a negociaciones alternativas mediante mecanismos de poder y concentración de los principales recursos; así como una situación paradójica en torno a la hacienda, dado que mantenía una estructura organizacional tradicional, pero aún así, logró concretar significativos avances en sus sistemas productivos. ${ }^{70}$

En lo que concierne al desempeńo urbano, aún en la primera mitad del siglo XIX, un elemento común en los debates de la vida pública de las ciudades europeas fue la constante alusión a los niveles de las cosechas del temporal en turno, así como a las perspectivas para los siguientes ańos. Con la evolución de la agricultura comercial estas contingencias se superaron. ${ }^{71}$

El surgimiento de la agricultura comercial también favoreció la aparición de nuevas tareas en campo, como las manufacturas, que contribuyeron en la complejidad del sistema productivo. Incluso, en el caso de Japón, durante la era Tokuwaga, esto produjo algunas fricciones sociales entre propietarios rurales y urbanos, dado que este fenómeno representaba una dislocación de las antiguas formas de trabajo y una reconfiguración de las redes de transporte. ${ }^{72}$ En otros contextos, como lo fue Rusia durante el siglo xIx, resultaba complicado concebir el advenimiento de la protoindustrialización desvinculada de la agricultura con una orientación hacia el mercado, sustentada en el excedente agrícola y en la participación de las clases

${ }^{70}$ Arij Ouweneel, "Don Claudio Pesero y la administración de la hacienda de Xaltipan (Tlaxcala), 1734-1737”, en Arij Ouweneel y C. Torales Pacheco, coords., Empresarios, indios y Estado. Perfil de la economía mexicana (siglo XVIII), México, Universidad Iberoamericana, 1992, pp. 258, 261 y 285; Tortolero, op. cit., 2008, 42, 45, 98 y 291.

${ }^{71}$ Wrigley, op. cit., 1992, 168; Bairoch, op. cit., 1983, 486 y 489.

72 James L. McClain, "Bonshogatsu. Festivals and State Power in Kanazawa”, en Monumenta Nipponica, 47:2, 1992, 187; Wigen, op. cit.,1992, 20. 
altas urbanas mediante el financiamiento de trabajadores en el campo. ${ }^{73}$ Para las experiencias latinoamericanas, no obstante el peso de las actividades mineras en la estructura productiva y del comercio exterior, la agricultura fue uno de los principales empleadores. ${ }^{74}$ Por lo que respecta a Colombia, durante las primeras décadas del siglo XIX, el predominio de una agricultura comercial de exportación, disminuyó los incentivos de los habitantes del medio rural para producir manufacturas, a ello se agregaron las dificultades del tráfico comercial interno, lo que en última instancia se manifestó en la evolución de la estructura productiva colombiana. ${ }^{75}$ En el Valle de México durante el siglo XVIII, el mercado interregional reflejó en buena medida esta complejidad del sistema productivo en torno a la comercialización de la agricultura y a los arreglos institucionales vinculados con ésta, una situación parecida se observó en otros espacios de la Nueva España y América Latina. ${ }^{76}$ Salvo que en América del Sur el incremento en la circulación de dinero, además de ser una manifestación de la madurez de los sistemas productivos locales, se extendió hacia los mercados externos al permitir la distribución de productos agrícolas y lograr la inserción de estos espacios latinoamericanos en el exterior, lo que impactó las estructuras agrarias tradicionales. ${ }^{77} \mathrm{En}$ suma, se puede mencionar que el desenvolvimiento de la actividad agrícola con orientación al mercado, o la falta de mecanismos para impulsar dicha actividad, se reflejó en el desempeño del sistema económico y en sus interconexiones con otras esferas productivas, lo que marcó una notable diferenciación en el tipo de crecimiento.

${ }^{73}$ Melton, op. cit., 1987, 92 y 105.

${ }^{74}$ Chiaramonte, op. cit., 1984, 189.

${ }^{75}$ Albert Bery, "The Limited Role of Rural Small-Scale Manufacturing for Late-comers: Some Hypotheses on the Colombian Experience", en Journal of Latin American Studies, 19:2, 1987, 306.

${ }^{76}$ Ouweneel y Bijleveld, op. cit., p. 554; Bushnell, op. cit., 2003, 123.

77 John Lynch, "Los factores estructurales de la crisis: La crisis del orden colonial”, en G. Carrera y J. Lombardi, coord., La crisis estructural de las sociedades implantadas. Historia General de América Latina, vol. v, París, unesco, Trotta, 2003, 36; Nelson Manrique, "Las sociedades originarias en el ámbito de la formulación inicial de los proyectos nacionales como culminación de los procesos de continuidad y ruptura", en G. Carrera y J. Lombardi, coords., La crisis estructural de las sociedades implantadas. Historia General de América Latina, vol. v, París, unEsco, Trotta, 2003, 361. 


\section{EL INCREMENTO DEL TRABAJO NO AGRÍCOLA}

Es común concebir a los campesinos como trabajadores dedicados exclusivamente a cultivar la tierra para producir alimentos o materias primas. Pero la investigación ha demostrado que también invirtieron parte de su tiempo en tareas no agrícolas para completar su ingreso y mantener su nivel de vida. Por lo tanto, resulta importante conocer qué tipo de actividades complementarias se han llevado a cabo en el campo. En un principio se pensó que dicho fenómeno proliferó sólo en áreas agrícolas deprimidas, pero se ha comprobado también que surgió en lugares con alta productividad. Si partimos de la temporada muerta, resulta que existieron diversas oportunidades para impulsar el trabajo alternativo como la producción manufacturera para el autoconsumo y el mercado. Lo anterior representó un ingreso extra, ganancia esporádica pero trascendente para las estrategias económicas del núcleo doméstico campesino.

Por lo tanto, cada vez se encuentra con mayor frecuencia la aceptación de una amplia diversidad laboral en el entorno agrario como un elemento inherente a los estilos de vida del campesinado bajo una triple dimensión: espacial, sectorial y cronológica. A partir de ello es factible dibujar con mayor precisión los contornos de los contextos agrarios. ${ }^{78}$ Entonces, los elementos cruciales fueron el incremento del tiempo de trabajo en actividades no agrícolas, con respecto a las tareas tradicionales, y su impacto en los estilos de vida. Este contexto fue clave para impulsar la protoindustrialización. Cuyo fenómeno se manifestó en áreas con limitaciones para el crecimiento agrícola y en lugares con alta productividad. En ambos casos influyeron factores como el desempeńo, tamaño o tipo de propiedad e intensificación en el uso del suelo.

Por otra parte, también es común encontrar estimaciones bajas sobre los niveles de empleo en actividades no agrícolas, lo anterior obedece a las dificultades de llevar a cabo una observación detallada

${ }^{78}$ Roland Hubscher, "De la integración del campesinado en la sociedad global: la pluriactividad ¿̨un equilibrio o una desestabilización de la sociedad rural?”, en Serie de Traducciones, núm. 1, Universidad Nacional del Mar de la Plata, 1996, 4. 
al respecto. A pesar de ello, se ha logrado documentar en el contexto europeo alta proporción de miembros de grupos domésticos rurales dedicados a las tareas del hilado y tejido. ${ }^{79}$ Mientras que en la Nueva España los datos fiscales del siglo XviII, que registraban las actividades de los indígenas, revelaron diversas estrategias que giraban en torno a la comercialización o producción de artesanías en pequeña escala en comunidades cercanas a las principales ciudades. De igual forma, la investigación en Nueva Galicia y territorios centroamericanos reveló situaciones similares al finalizar el siglo XVIII. ${ }^{80}$

Por lo tanto, se observa que diversos factores influyeron en la proliferación de otras actividades en el entorno agrario, donde destaca el espectro que abarcó a las manufacturas. Las situaciones que contribuyeron a ampliar el número de artesanos en el medio rural fueron los periodos de depresión económica, lo cual afectó a los hogares que vivían en el umbral de subsistencia dada la disminución de los ingresos relativos, también repercutió la transición hacia la ganadería lo que liberó mano de obra, las condiciones tecnológicas, los bajos salarios, los largos inviernos que dejaban poco tiempo para las faenas agrícolas, la presión demográfica o la escasez de tierras, incluso, para el caso de Italia se ha señalado el impulso del Estado a fin de promover a los pequeños propietarios rurales.$^{81}$ Hechos que en su conjunto contribuyeron a la especialización manufacturera por parte de algunos campesinos, además, estas estrategias tuvieron consecuencias en las estructuras de los hogares, lo cual se constituyó como uno de los ingredientes clave en la industrialización. Es decir, los permanentes niveles de subsistencia en el contexto agrario y la existencia de un grupo de campesinos que diversificaron sus actividades fueron factores idóneos para impulsar la protoindustrialización.

${ }^{79}$ Ulrich Pfister, "Work Roles and Family Structure in Proto-Industrial Zurich", en Journal of Interdisciplinary History, 20:1, 1989, 101.

${ }^{80}$ Horst Pietschmann, "Agricultura e industria rural indígena en el México de la segunda mitad del siglo xviII", en Arij Ouweneel y C. Torales Pacheco, coords., Empresarios, indios y Estado. Perfil de la economía mexicana (siglo XVIII), México, Universidad Iberoamericana, 1992, 124; Bauer, op. cit., 2003, 299.

${ }^{81}$ Terence McInthos, "Schwabish Hall, 1650-1750: Urban Social and Economic Life in Southwest Germany After the Thirty Years' War", en Journal of Economic History, 51:2, 1991, 463; Howell, op. cit., 1992, 277; Dewerpe, op. cit., 1985, p. viii 
Durante la temporada muerta los campesinos elaboraban descentralizadamente algunas manufacturas para consumo propio, como una ocupación alternativa gracias a que el costo de oportunidad del tiempo dedicado a la agricultura era prácticamente nulo. Incluso, en Europa a partir del siglo xvIII era común encontrar trabajadores en el campo que manufacturaban sus propias herramientas motivados por la creciente productividad agrícola, situación que abrió la puerta a la innovación y simultáneamente sirvió de sustento a un sistema productivo que devenía más complejo. ${ }^{82} \mathrm{Si}$ a ello se agrega la disposición de capital fijo y circulante se tiene como resultado que estas actividades fueron aún más atractivas para los habitantes del campo. Pero, en amplias regiones los productos agrícolas eran aún la base de la subsistencia, además marcaron los ritmos y tiempos de la producción manufacturera. ${ }^{83}$

La aparición de actividades alternativas fue irregular a través del tiempo y espacio, a veces se presentaba en un entorno agrario alejado de las zonas más urbanizadas, en otras ocasiones en los alrededores de ciudades pequeñas que sufrían una depresión económica. ${ }^{84}$ Por lo que corresponde al último caso, algunas concentraciones urbanas menores en Europa vieron en las manufacturas de carácter rural una opción para salir adelante. En las ciudades rusas de Pavlovo e Ivanovo se construyeron redes productivas protoindustriales con base en la servidumbre para impulsar sus sistemas económicos; la persistencia y extensión de una protoindustrialización sustentada en la servidumbre entre los siglos XVIII y XIX ha llamado la atención de los historiadores. ${ }^{85}$ En lo que concierne a España, desde el siglo xvir se registró una creciente producción manufacturera rural en el rubro textil, aunque débilmente organizada al principio, tendió a mejorar su estructura organizacional, hecho que le permitió incrementar su

${ }^{82}$ Bairoch, op. cit., 1983, 501.

${ }^{83}$ Alain Dewerpe, "Genèse proto-industrielle d'une région développée: l'Italie septentrionale”, en Annales, Économie-Sociétés-Civilisations, 39:6, 1984, 900; Carlo M. Belfanti, "Rural manufactures and rural proto-industries in 'Italy of the Cities' from the sixteenth through the $18^{\text {th }}$ century", en Continuity and Change, 8:2, 1993, 258-267.

${ }^{84}$ Wrigley, op. cit., 1992, 249.

${ }^{85}$ Melton, op. cit., 1987, 77; Rudolph, op. cit., 1985, 67. 
producción dirigida hacia el mercado. ${ }^{86}$ En otros lugares de Europa el constante ingreso derivado de actividades artesanales que incentivó a los grupos domésticos a invertir cada vez más tiempo y recursos en la producción manufacturera para ampliar sus horizontes económicos. ${ }^{87}$ En Japón se presentó un escenario similar entre 1830 y 1844 derivado del incremento e intensidad del comercio internacional, eventos que impulsaron la circulación de dinero en regiones rurales mediante una red interbancaria, que abrió la posibilidad de incrementar la eficiencia productiva, movilidad de recursos y oferta monetaria para los hogares inmiscuidos en la protoindustrialización. ${ }^{88} \mathrm{El}$ incremento en la circulación monetaria de Japón llama la atención para las experiencias latinoamericanas, debido a que según se ha constatado en otras investigaciones, los terratenientes o administradores se rehusaron constantemente a pagar en moneda a los respectivos trabajadores en el campo, sobre todo si éstos tenían la capacidad de producir artesanías que facilitaran su subsistencia. ${ }^{89}$

No obstante que en la mayoría de los casos el desenvolvimiento de la protoindustrialización se presentó en contextos agrícolas relativamente deprimidos, también se han detectado eventos donde el impulso de otras actividades repercutió de manera positiva en la producción manufacturera, tal y como sucedió con el incremento de la extracción de plata en la Nueva Espańa. ${ }^{90}$ Pero cuando el boom de la plata terminaba, los condiciones económicas en general se veían perjudicadas en el campo, por lo tanto, algunos de sus habitantes emigraban hacia la ciudad en busca de nuevos empleos debido a que las manufacturas de tipo rural no representaban una alternativa, salvo en los alrededores de algunos centros manufactureros bien identificados como Querétaro, Puebla, Guadalajara o Ciudad de México. ${ }^{91}$

${ }^{86}$ González, op. cit., 1984, 17.

${ }^{87}$ O’Brien, op. cit., 1996, 231.

${ }^{88}$ Ronald P. Toby, "Both a Borrower and Lender Be. From Village Moneylender to Rural Banker in the Tempo Era”, en Monumenta Nipponica, 46:4, 1991, 485.

${ }^{89}$ Bauer, op. cit., 2003, 297.

${ }^{90}$ Ouweneel y Bijleveld, op. cit., 1989, 556.

${ }^{91}$ Bushnell, op. cit., 2003, 110. 
Un evento clave que distinguió a las sociedades protoindustriales de sus similares preindustriales fue que la elaboración de manufacturas estrechó sus vínculos con la producción agraria. ${ }^{92}$ En el caso de la localidad española de Jaén existieron manufacturas en el campo que llegaron a emplear más de mil personas durante el siglo XVIII, mientras que en las regiones agrarias de Sevilla y Granada la elaboración de paños era importante así como las bayetas en San Juan de Alfarache, Carmona y Ecija. ${ }^{93}$ En Rusia, el sistema servil aprovechó las condiciones del mercado para impulsar la producción manufacturera en el medio rural, dicha situación causó cierta sorpresa si se toma en cuenta que este sistema organizativo se convirtió en un promotor de la industrialización sin un mercado de mano de obra propiamente dicho, debido a que el trabajo de carácter servil no podía contratarse de manera libre. ${ }^{94}$

Entre los siglos XVIII y XIX en la región de Pasto, en la Nueva Granada, existían pequeños propietarios agrícolas que también producían textiles de algodón y lana para el autoconsumo, lo que les permitió incrementar su ingreso disponible. Incluso, en otros espacios latinoamericanos se tienen testimonios sobre la producción de herramientas de campo para impulsar las faenas agrícolas. Mientras que en la Nueva España no se descartaba la posibilidad de encontrar tejedores-campesinos en los rubros de algodón o lana. De esta forma se incorporaron diversos habitantes del medio rural en tareas manufactureras dadas las oportunidades que se brindaban en sus respectivos contextos. ${ }^{95}$

Cuando se incrementó el trabajo no agrícola en el medio rural el grupo doméstico devino una organización crucial. La combinación de tareas agrícolas y manufactureras transformó la vida de las familias campesinas, cuyos miembros se convirtieron en campesinosartesanos, como parte de un proceso hacia la proletarización. ${ }^{96}$

${ }^{92}$ Kriedte, Medick y Schlumbohm, op. cit., 1986, 143.

${ }^{93}$ González, op. cit., 1984, 19.

${ }^{94}$ Rudolph, op. cit., 1985, 59.

${ }^{95}$ Miño, op. cit., 1998, 149; Bery, op. cit., 1987, 299; Bauer, op. cit., 2003, 298.

${ }^{96}$ David Levine, "Asymmetrical, non-linear population dynamics", en R. Leboutte, coord., Proto-industrialisation. Recherches récentes et nouvelles perspectives, Genève, Droz, 
Entonces, la protoindustrialización se tornó un asunto familiar por excelencia, especialmente en tiempos de crisis o caídas de los ingresos tradicionales. Este fenómeno encontró una de sus expresiones en Europa al impactar la dinámica demográfica y modificar la estructura organizacional del trabajo a domicilio. ${ }^{97}$

Otro elemento que jugó a favor del grupo doméstico fue el aumento global de la productividad, especialmente si se concibe a este conjunto como una unidad de producción. Lo anterior se explica al tomar en cuenta que el costo de inmiscuir un miembro más del grupo en las tareas manufactureras era bajo, sobre todo en un contexto donde la mano de obra era barata, debido a que eran las mujeres o los nińos quienes se agregaban a este tipo de ocupaciones. Tradicionalmente las mujeres podían dividir parte de su tiempo entre las funciones que cumplían al interior del hogar y la elaboración de manufacturas, mientras que los hombres hacían lo propio alternando con las faenas en el campo. ${ }^{98}$ Por lo general, el grupo doméstico de carácter campesino no se concentraba en producir valor de cambio, sino más bien, valor de uso. ${ }^{99}$ Si el papel del trabajo servil y la función de la economía campesina en la dinámica protoindustrial en la Rusia de los siglos XviII y xix ha llamado la atención, no deja de sorprender también el papel de los esclavos en Minas Gerais durante el periodo colonial tardío en Brasil, donde se localizaron grupos domésticos que utilizaban mano de obra esclava para hilar y tejer como una especie de estrategia campesina de subsistencia. ${ }^{100}$

1996, 100; R. Leboutte, "Adaptation, reconvertions, mutations. Le rôle de la proto-industrialisation dans la genèse du bassin industriel Liégeois", en R., Leboutte, coord., Proto-industrialisation..., 1996, 290.

${ }^{97}$ Rab Houston y K.D.M. Snell, "Proto-Industrialization? Cottage Industry, Social Change, and Industrial Revolution”, en The Historical Journal, 27:2, 1984, 479.

${ }^{98}$ Sokoloff, Kenneth y Dollar, David, "Agricultural seasonality and organization of manufacturing in Early industrial economies: The contrast between England and the United States", en The Journal of Economic History, 57:2, 1997, 294.

${ }^{99}$ Peter Kriedte, Peasants, landlords and merchant capitalist, Londres, Berg Publishers, $1983,2$.

${ }^{100}$ Rudolph, op. cit., 1985, 52; Libby, op. cit., 1997, 106. 


\section{RETROALIMENTACIÓN ENTRE LA AGRICULTURA}

\section{Y LAS MANUFACTURAS}

La retroalimentación entre agricultura y manufacturas se vio favorecida con la creciente aparición de pequeños propietarios. El progreso agrícola en algunas regiones rurales se acompañó con el surgimiento del trabajo a domicilio, tanto en espacios donde predominaba una economía de subsistencia como en aquellos donde existían condiciones de vida más holgadas. En un principio se pensó que lo anterior constituía un factor de movilidad social, pero, investigaciones más exhaustivas al respecto, señalan que en los Países Bajos al intensificarse los trabajos agrícolas el precio de la tierra aumentó en el siglo XVIII, lo que incentivó aún más la proliferación del trabajo a domicilio y, simultáneamente, los propietarios se sintieron motivados a dividir sus terrenos para venderlos. Es decir, se manifestaron los primeros síntomas de la proletarización en un contexto donde se producían mercancías. ${ }^{101}$

Por lo que corresponde a América Latina, históricamente la industria rural y el trabajo a domicilio no han llamado mucho la atención en los debates públicos, es decir, no se han tomado en su justa dimensión sus contribuciones al proceso de industrialización. Lo anterior se explica en gran parte por los bajos niveles de productividad registrados a través del tiempo, las precarias condiciones en las que se llevan a cabo los trabajos y la falta de una conexión evolutiva hacia otras formas de producción más complejas. Pero esto no significa que carezcan de importancia histórica las Pup, dado que su lógica ha sido distinta si la comparamos con otras unidades productivas. De esta forma, se corrobora mediante la experiencia de la Nueva Granada en el siglo XviII que existía una cantidad notable de minifundios donde se elaboraban y suministraban manufacturas para el consumo local. Algo similar se registró en las ciudades pequeńas que se interconectaban con economías campesinas. En lo que conocemos ahora como Colombia, desde el siglo XIX se hizo evidente la relación entre producción agrícola y manufacturera, debido a que

${ }^{101}$ Mendels, op. cit., 1976, 203; Mendels, op. cit., 1984, 944 y 947. 
ésta última actividad era una fuente alternativa de ingreso y cubría parte de las necesidades de los grupos familiares inmiscuidos en dicha esfera productiva. ${ }^{102}$ En el caso de Nueva España durante la segunda mitad del siglo XVIII, también destacó el trabajo de artesanos indígenas que participaban en las obras públicas, la comercialización de sus productos y la venta de mano de obra; estrategias que les permitieron indagar en transacciones con alto grado de monetarización y vincularse con la dinámica económica de sus respectivas regiones. Asimismo, en la ciudad Quito y las regiones montañosas aledañas sobresalió la producción de textiles en pequeña escala. Quito formó parte de un sistema andino de comercio con un radio de acción amplio, pero la pérdida de algunos mercados textiles marginó paulatinamente a este centro urbano de los circuitos de intercambio en el cono sur. ${ }^{103}$ Durante este tiempo una situación latente para las manufacturas latinoamericanas fue la presión recibida por sus similares provenientes de Europa, que en algunos casos fueron capaces de desplazar la producción interna.

Si en América Latina este proceso se manifestó como parte natural de un sistema productivo que tendía hacia la complejidad, un fenómeno diferente se vivió a principios del siglo XIX en Egipto, donde se impulsó una reforma agraria por parte del Estado con el objetivo de estimular la producción agrícola. El protagonista de dicha iniciativa fue el Muhammad' Ali Pasha de El Cairo, quien transformó el valle de El Nilo en una enorme granja para concentrar recursos e incentivar artificialmente al ejército y la industrialización sustentada en la producción masiva de granos y algodón. ${ }^{104}$

Diversos agentes económicos inmersos en el contexto agrario canalizaron sus recursos hacia la promoción de las manufacturas gracias al incremento de la productividad agrícola. Lo anterior se acentuó aún más en regiones donde la agricultura comercial y la protoindustrialización fueron compatibles, a tal grado de retroalimentarse de forma mutua. Una situación contraria había sido previs-

${ }^{102}$ Bery, op. cit., 1987, 295 y 296.

${ }^{103}$ Pietschmann, op. cit., 1992, 123; Bushnell, op. cit., 2003, 119.

${ }^{104}$ Jean Batou, "Nineteenth-Century attempted escapes from the periphery: the cases of Egypt and Paraguay", en Review Fernand Braudel Center, 26:3, 1993, 283. 
ta inicialmente por el modelo, pero se han documentado ejemplos que contradicen sus postulados como en la región de Pays de Caux y el sureste de la India. En el primer espacio se llevaron a cabo actividades agrícolas dirigidas hacia el mercado combinadas con la promoción manufacturera. ${ }^{105}$ Mientras que en el segundo, abundó la producción de tejidos gracias a la proliferación de materias primas. ${ }^{106}$ Entonces, se puede argumentar que la disponibilidad de mano de obra fue clave para impulsar este modo de producción, independientemente del tipo de agricultura que prevaleció en las regiones.

Por lo tanto, es indispensable no visualizar la protoindustrialización como una actividad ajena al resto de la economía rural, por el contrario, su orbita económica abarcaba a las actividades agrícolas y manufactureras como parte de un fenómeno integrado y crecientemente complejo. Esta dinámica no sólo respondió a las ventajas que se presentaban en torno a las redes de distribución, sino también, a los impulsos originados de la matriz institucional, donde destacó la intervención del Estado, que en última instancia permitían a los grupos dominantes apropiarse de una porción considerable del producto final y marcar la pauta sobre el tipo de industrialización que se construía a través del tiempo, en un contexto donde la diversidad fue clave para el funcionamiento de las estructuras productivas. Por su parte, los campesinos-propietarios y el incipiente proletariado agrícola continuaron con sus estrategias sustentadas en la pluriactividad, donde se incluían tareas como la elaboración de herramientas para el campo en las pequeńas fundiciones, actividades que representaban en ese momento un trabajo secundario pero que iba mucho más allá de la subsistencia. ${ }^{107} \mathrm{~A}$ pesar de lo mencionado, en las etapas iniciales de la industrialización en Europa todavía el valor global de la producción de bienes agrícolas superaba a su similar de tipo manufacturero, pero era evidente el aumento de éste en términos relativos y absolutos, así lo presentía incluso Adam Smith en sus

${ }^{105}$ Gullicson, op. cit., 1983, 837 y 848.

106 Sanjay Subrahmanyam, "Rural Industry and Commercial Agriculture in Late Seventeenth-Century South-Eastern India”, en Past and Present, 126, 1990, 86 y 92.

${ }^{107}$ Kriedte, Medick y Schlumbohm, op. cit., 1986, 16 y 211; Cailly, op. cit., 1993, 34; Butlin, op. cit., 1986, 5; Melton, op. cit., 1987, 81; Bairoch, op. cit., 1983, 482. 
textos cuando asociaba la prosperidad en el campo con el auge de las manufacturas, creencias que después fueron ratificadas con base en los inventarios levantados a finales del siglo XVIII en diferentes regiones europeas. ${ }^{108}$

Otro escenario favorable para la articulación de manufacturas, agricultura comercial y actividades alternativas en el campo se presentó en Japón durante las épocas Tokugawa y Meiji al impulsarse la participación social en torno a la elaboración de artesanías, e incluso, se organizaron criaderos de peces para comercializar los productos en el exterior. Dichas estrategias fueron apoyadas por las elites gracias al levantamiento de restricciones y privilegios que afectaban las iniciativas económicas y la movilización de recursos. ${ }^{109}$

Por otra parte, a mediados del siglo XviıI en la provincia española de Galicia, algunas materias primas para hacer tejidos pasaban directamente del campo al trabajo artesanal mediante el mismo grupo de doméstico, esta manifestación fue hasta cierto punto común en el resto de Europa como lo muestran las investigaciones sobre norte de Italia durante el siglo xIx en el rubro de la seda o el lino. Mientras que la ruta del producto final fue distinta. En Galicia se distribuyó por los canales tradicionales, situación que facilitó el mantenimiento de relaciones comerciales con otras ciudades y localidades cercanas. En Murcia se detectó una estrecha relación entre la producción manufacturera y la arriería en el marco de labores complementarias. También a mediados del siglo XviII la producción lanera de Cataluña experimentó un auge sustentado en la especialización e intensificación de cultivos, estrategias que permitieron superar las típicas oscilaciones de antiguo régimen al manifestarse el flujo de recursos entre la agricultura comercial y la elaboración de manufacturas en el campo. ${ }^{110}$ Otra experiencia que coincide con

${ }^{108}$ John Smail, "Manufacturer or artisan? The relationship between economic and cultural change in the early stages of the eighteen-century industrialization", en Journal of Social History, 25:4, 1992, 795 y 796.

${ }^{109}$ Meg Nakano, "Book Review: Japan's Proto-industrial Elite", en Reviews in the Humanities and Social Sciences, junio, 2000, 2; John Lee, "Trade and Economy in Preindustrial East Asia, c. 1500-c. 1800: East Asia in the Age of Global Integration", en The Journal of Asia Studies, 58:1, 1999, 6.

${ }^{110}$ Xan Carmona Badía, "Clases sociales, estructuras agrarias e industria rural domésti- 
este tipo de transferencias se ubicó en Rusia entre los siglos XVIII y XIX, el proceso manufacturero se desenvolvió en un contexto de mano de obra no libre bajo una dinámica protoindustrial y la prestación de servicios laborales; el denominador común en ambos sistemas fue la influencia de las estructuras agrarias en la organización del trabajo. ${ }^{11}$ Entonces, tenemos que en términos generales para Europa, entre los siglos XVIII y XIX, las actividades artesanales se asociaron con la producción de granos y la especialización regional, lo que facilitó el flujo de recursos entre ambas tareas. En la Unión Americana la situación fue distinta, la abundancia relativa de mano de obra y tierra no permitió una imbricación estrecha. ${ }^{112}$

En el siglo XIX, encontramos otros testimonios con una lógica similar sustentados en las políticas estatales impulsadas en Paraguay y Egipto. Los respectivos Estados canalizaron recursos derivados de los excedentes agrícolas para diseñar proyectos pilotos de mecanización mediante el impulso de una nueva elite encargada de garantizar la continuidad de los mismos, pero, una serie de dificultades se presentaron al momento de llevarlos a la práctica, donde destacó la intermitente dotación de materias primas. En el largo plazo se abandonaron las iniciativas ante las dificultades que se enfrentaron para materializar las ventajas que se pretendían obtener. ${ }^{113}$

En Nueva España fue común durante los siglos XviII y XIX encontrar una especie de complejo agrario-manufacturero en torno a la organización empresarial de las haciendas, gracias a la cantidad de recursos que estas unidades productivas acumulaban; de tal forma que algunas instalaciones agrícolas fueron adaptadas en las fincas para elaborar tejidos dada la importancia que adquirió la producción artesanal en diversas regiones novohispanas. Pero las condiciones institucionales prevalecientes, control férreo de los recursos concentrados en pocas manos y desincentivos en los mercados complementarios, redujeron las posibilidades de evolución hacia el siste-

ca en la Galicia del siglo xvıII", en Revista de Historia Económica, 2:3, 1984, 41; González, op. cit., 1984, 19; Torras, op. cit., 1984, 126.

${ }^{111}$ Melton, op. cit., 1987, 72.

${ }^{112}$ Sokoloff y Dollar, op. cit., 1997, 295 y 306.

${ }^{113}$ Batou, op. cit., 1993, 295. 
ma fabril por parte de las manufacturas. A pesar de ello, es importante subrayar que no solo existía la elaboración de tejidos localizados bajo la influencia de la hacienda, sino también, coexistió una amplia gama de campesinos-artesanos tal y como se evidenció en torno a la ciudad de México y Puebla en la segunda mitad del siglo XVIII y primera del siglo XIX, donde abundaron las PUP como una alternativa en un contexto agrario caracterizado por la recuperación demográfica. ${ }^{114}$ Algo distinto ocurría en la economía andina, debido a que en estos lugares fueron expresamente construidas instalaciones para hacer telas pero su estructura física fue de menor calidad con respecto a la Nueva España; independientemente de ello, lograron conectar dentro de una misma lógica las iniciativas del campo y la ciudad. En otros espacios coloniales, como Cuba y la Capitanía General de Venezuela, el movimiento de recursos agrícolas era importante pero no logró estimular de manera amplia las manufacturas, la exportación de productos primarios consumió muchos de los recursos generados en el ámbito rural. ${ }^{115}$

A partir del siglo XVIII, la transferencia de recursos entre agricultura y manufacturas implicó una reorganización del grupo doméstico para hacer frente al nuevo panorama económico en Europa; es decir, se ejerció una retroalimentación entre los hogares inmiscuidos en la protoindustrialización y las estructuras institucionales prevalecientes en el ámbito político-económico. ${ }^{116}$ Incluso, la dimensión del grupo doméstico implica una reconsideración histórica importante, debido a que en Europa Oriental estas unidades tradicionalmente contaron con más miembros si se comparan con sus similares en occidente. Dicha situación influyó en la estrategia productiva, sobre todo si se toma en cuenta que aún este tipo de hogares se veían más afectados por los ciclos inherentes a la agricultura, si se comparan con los impactos derivados de los vaivenes en los mercados ma-

${ }^{114}$ Manuel Miño, op. cit., 1998, 146; Arij Ouweneel, op. cit., 1989, 403.

${ }^{115}$ Catalina Banko, "Las casas comerciales y la economía agroexportadora en Venezuela”, en Carta Económica Regional Nueva Época, 21:104, 2010, 7; Miño, op. cit., 1993, 44.

${ }^{116}$ François M.M. Hendrickx, "From weavers to workers: demographic implications of an economic transformation in Twente (The Netherlands) in the nineteenth century", en Continuity and Change, 8:2, 1993, 332; Mager, op. cit., 1993, 192. 
nufactureros. ${ }^{117}$ Pero una vez que se incrementó la productividad agrícola, se abrió la posibilidad de emigrar hacia otros espacios, un factor más que repercutió en la vida de los grupos domésticos dada la disminución relativa de los precios, así como el incremento en la oferta de bienes primarios y alimentos.

Otro aspecto clave del grupo doméstico radicó en su localización. Algunos de ellos se mudaron hacia los perímetros urbanos para aprovechar las articulaciones que se gestaban entre el campo y la ciudad, o en el caso de concentraciones con menor densidad se vincularon directamente con el medio rural como sucedió en suroeste de Alemania entre los siglos XVII y xvIII. En cualquiera de las dos experiencias, estos grupos domésticos atendieron con mayor interés los requerimientos del empleo permanente, como lo fue la producción manufacturera. El fenómeno de movilidad en torno a las ciudades no fue exclusivo de Europa, aunque sus causas fueron diferentes dada la crisis por la que pasaba el agro novohispano a finales del siglo XviII, también se presentó en los alrededores de las ciudades de México y Puebla, donde se localizaron diversos campesinos-artesanos en busca de una mejor paga dentro del sistema manufacturero a domicilio que se había establecido en estos núcleos urbanos. ${ }^{118}$ En otros casos las exigencias de los mercados externos orillaron a los miembros del grupo doméstico a especializarse y mejorar sus técnicas productivas mediante la utilización del conocimiento acumulado en torno a las actividades manufactureras; por ejemplo, en el norte de Italia con la producción de seda en el siglo xVIII. Pero aún así, las estrategias de tipo protoindustrial por lo general no se caracterizaron por impulsar la innovación, sino más bien, funcionaron como un regulador socioeconómico ante el crecimiento demográfico. ${ }^{119}$

En la mayoría de contextos históricos donde apareció la protoindustrialización se revelaron cambios estructurales en la organización

${ }^{117}$ Richard Rudolph, "Family Structure and Proto-industrialization in Russia", en The Journal of Economic History, 40:1, 1980, 115.

${ }^{118}$ Ouweneel, op. cit., 1989, 405.

${ }^{119}$ Pierre Deyon, "Fécondité et limites du modèle protoindustriel: permier bilan", en Annales, Économies-Sociétés-Civilisations, 39:6, 1984, 870; Dewerpe, op. cit., 1985, 478. 
de las familias campesinas. Lo anterior se manifestó tanto en las épocas de Tokugawa y Meiji en Japón como en las experiencias de Europa y la India. Por lo que corresponde a Japón, la relativa continuidad sociocultural entre Tokugawa y Meiji se reflejó en la persistencia del patrón de industrialización, el cual se reforzó gracias a las instituciones que prevalecieron en el medio rural y a los eficientes métodos de control sociopolítico del periodo Meiji. ${ }^{120}$ Mientras que en Europa Occidental los impactos de la protoindustrialización también influyeron en las formas organizativas de los grupos domésticos cuya dinámica básica radicaba en las limitaciones del ingreso agrícola. Aún en regiones donde se practicaba una agricultura comercial se evidenció este fenómeno, como en Pays de Caux. De tal forma que los grupos domésticos se vieron obligados a complementar el ingreso mediante la producción manufacturera, donde participaron los niños y mujeres, ya que en algunos casos como en Espańa, el trabajo de los varones era requerido con mayor intensidad en los campos, mientras que las actividades femeninas e infantiles fueron por lo regular más flexibles desde las perspectivas de los ritmos y lugar de trabajos, así como circunstancias vinculadas con el temporal. ${ }^{121}$

Dentro de este orden de ideas, en Rusia y en gran parte de Europa Oriental el surgimiento de actividades artesanales en el campo respondió a las pobres condiciones en las cuales se desenvolvía la agricultura, de tal forma, que el inicio de las labores manufactureras, como una estrategia secundaria, se dirigía a satisfacer un mercado de carácter local, a su vez ahí podían obtener los principales alimentos y así complementar el ingreso de los hogares. ${ }^{122}$ En la India entre los siglos XVIII y XIx los grupos domésticos llevaban a cabo un amplia variedad de tareas económicas complementarias, de las cuales destacaron aquellas de carácter artesanal vinculadas con los cambios que se experimentaban en el campo. ${ }^{123}$

${ }^{120}$ Ian Inkster, Japanese industrialisation. Historical and cultural perspectives, Londres, Routledge, 2001, 40; Howell, op. cit., 1992, 270.

${ }^{121}$ Gullicson, op. cit., 1983, 842; González, op. cit., 1984, 22.

${ }^{122}$ Melton, op. cit., 1987, 75 y 88.

${ }^{123}$ Frank Perlin, "State Formation Reconsidered: Part Two", Modern Asian Studies, 19:3, 1984, 468; Subrahmanyam, op. cit., 1990, 111. 
En los dominios españoles de América también se manifestaron cambios estructurales en los grupos domésticos y otros actores del medio rural. Por lo que toca a los indígenas de la región central de Nueva España en el siglo xviıI, mediante la investigación se ha evidenciado la complejidad que adquirieron sus actividades económicas, debido a que no sólo han sido considerados como campesinos, sino también, existen testimonios sobre su participación en la producción manufacturera en pequeña escala, a través de las formas de sujeción del trabajo impulsadas por la matriz institucional prevaleciente. También se inmiscuyeron en tareas que incluían la comercialización y elaboración de artesanías dirigidas al mercado. Situaciones similares se han documentado para el resto de América Latina durante la misma época, donde el espectro de participación se amplió gracias a la difusión del trabajo a domicilio en el campo y ciudad. ${ }^{124}$

\section{Consideraciones finales}

La industrialización en general y el enfoque particular derivado de la protoindustrialización como modelo se componen de una serie de factores que se relacionan entre sí. De tal forma que este último puede ser deconstruido para analizar específicamente algunas de sus piezas. Aquí nos hemos concentrado fundamentalmente en las relaciones establecidas entre agricultura y protoindustrialización. Un elemento innovador de este paradigma fue la importancia que adquirieron las PUP en su estructura analítica, especialmente, las articulaciones derivadas entre lo urbano y rural. Como sucede con la mayoría de los modelos, la protoindustrialización como tal presentó límites que impulsaron una segunda generación de estudios protoindustriales. Sin embargo, uno de los hallazgos más importantes fue el análisis de la transición de los grupos domésticos como unidad económica, desde la perspectiva de la oferta y demanda. No obstante los cuestionamientos y limitaciones, hemos comprobado que la protoindustrialización aún es de utilidad para

${ }^{124}$ Pietschmann, op. cit., 1992, 117; Chiaramonte, op. cit., 1984, 175. 
enriquecer y guiar el análisis histórico. Pero es importante usarla con precaución para evitar apegarse a un rígido modelo que poco nos aportará para entender los cambios inherentes al proceso de industrialización.

Un elemento común en las sociedades protoindustriales fue la reorganización del espacio para atender las articulaciones derivadas entre lo rural y urbano. En este sentido, la producción doméstica de manufacturas tuvo un papel clave a partir del siglo XviII tanto en Europa, Asia o las Américas. A pesar de la detección de brotes de industrialización en diferentes contextos, los resultados no han sido predeterminados, lo crucial radicó en la continuidad o discontinuidad del proceso, lo que en última instancia definió escenarios que pueden incluir la transición hacia una sociedad industrializada, la desindustrialización o un impasse. Otro componente en común fue la coexistencia de actividades tradicionales en el campo con aquellas no tradicionales, donde destacan las manufacturas; lo anterior se logró gracias a las capacidades de las sociedades para materializar la disposición adicional de recursos, pero sobre todo, la habilidad de organizar estos recursos en sus respectivas áreas de influencia. También, la reorganización del espacio impulsó dos mecanismos básicos que favorecieron la evolución industrial, como lo fueron una disposición suficiente de alimentos para la creciente población asentada en los centros urbanos y una producción constante de materias primas que evitaba el surgimiento de cuellos de botella en las manufacturas.

La dinámica entre producción agrícola, incremento de la población y crecimiento urbano fue clave para impulsar la protoindustrialización entre los siglos XVIII y XIX. El incremento de la producción agrícola liberó recursos que tradicionalmente se empleaban en dicha actividad, que junto con el aumento demográfico y el crecimiento urbano incentivaron a los diferentes agentes económicos a diversificar la oferta de productos donde las manufacturas ocuparon un lugar importante. Mientras que las transformaciones en el grupo doméstico se dieron mediante una mayor inserción del trabajo femenino e infantil en la producción manufacturera dirigida hacia los mercados. El conjunto de estas articulaciones ha sido cru- 
cial para entender la lógica de la protoindustrialización y sus respectivas derivaciones que han impactado a la industrialización en general y sus vinculaciones con la agricultura en particular.

El surgimiento de actividades no tradicionales en el campo fue importante para la protoindustrialización, pero aún más trascendente fueron el incremento en el tiempo de trabajo, así como, la participación sistemática de mujeres y niños en tareas manufactureras. Lo anterior transformó las estrategias y estructuras organizacionales del grupo doméstico al ampliar las posibilidades económicas en un medio caracterizado por la subsistencia. Por lo tanto, la producción de manufacturas tomó mayor regularidad a tal grado de coexistir permanentemente con las faenas tradicionales realizadas en el campo, hecho que le imprimió una dinámica especial a la protoindustrialización en un contexto de cambio.

Conforme las actividades agrícolas mostraron mayor dinamismo los agentes económicos canalizaron más recursos para promover las manufacturas en el campo, lo cual funcionó como un mecanismo de retroalimentación. Las articulaciones entre agricultura y protoindustrialización no sólo impactaron el medio rural, sino que también repercutieron en el funcionamiento de la economía urbana, que tuvo un papel clave para promover dicha relación como un mecanismo exógeno. A pesar de ello, las estrategias protoindustriales no se caracterizaron por impulsar la innovación tecnológica ahorradora de mano de obra, más bien, funcionó como regulador socioeconómico en un contexto de crecimiento demográfico, dado que gran parte de su lógica descansó en promover una nueva estructura organizacional en el seno de los grupos domésticos que intentaban adaptarse a las condiciones económicas prevalecientes. Lo anterior fue un límite en la evolución hacia la consolidación de una sociedad industrializada en busca de un cambio tecnológico permanente con base en una incipiente economía del conocimiento. Cuando este último fenómeno se presenta, es necesario indagar sobre el funcionamiento de otros paradigmas que nos expliquen con mayor coherencia esta nueva etapa de la industrialización. 


\section{BIBLIOGRAFÍA CITADA}

A'Hearn, Brian, "Institutions, externalities, and economic growth in southern Italy: evidence from the cotton textile industry, 1861-1994", en Economic History Review, 51:4, 1998, 734-762. Adelman, Irma y Cynthia Taft Morris, “The Role of institutional influence in patterns of agricultural development in the nineteenth and early twentieth centuries: a cross-section quantitative study", en Journal of Economic History, 39:1, 1979, 159-176.

AhmaD, Ahrar, "Analyzing pre-colonial South Asia: mode of production or proto-industrialization", en Journal of Contemporary Asia, 27:3, 1997, 315-323.

Alter, George, Michel Oris y Muriel Neven, "When protoindustry collapsed fertility and the demographic regime in rural eastern Belgium during the Industrial Revolution", en Historical Social Research, vol. 32, núm. 2, 2007, 137-159.

Ashton, Thomas, La revolución Industrial, 1760-1830, México, FCE, 1983.

BAIroch, Paul, "La agricultura y la Revolución Industrial 17001914”, en C. Cipolla, coord., Historia económica de Europa. La Revolución Industrial, Barcelona, Ariel, 1983, 464-516.

BAnerJeE, Abhijit y Lakshmi IYer, "History, Institutions and Economic Performance: The Legacy of Colonial Land Tenure Systems in India”, en BREAD Working paper No. 003, Bureau for Research in Economic Analysis of Development, United States, 2003, 1-29.

BAnko, Catalina, "Las casas comerciales y la economía agroexportadora en Venezuela”, en Carta Económica Regional Nueva Época, 21:104, 2010, 7-18.

BATou, Jean, "Nineteenth-Century attempted escapes from the periphery: the cases of Egypt and Paraguay", en Review Fernand Braudel Center, 26:3, 1993, 279-318.

BAuer, Arnold, "Las estructuras agrarias en la América Española", en Historia General de América Latina, vol. vi, París, Unesco, Trotta, 2003, 295-314.

BAYLY, C.A., "State and economy in India over seven hundred years", en The Economic History Review, 38:4, 1985, 583-596. 
Belfanti, Carlo M., "Rural manufactures and rural proto-industries in 'Italy of the Cities' from the sixteenth through the $18^{\text {th }}$ century", en Continuity and Change, 8:2, 1993, 253-280.

BERG, Maxine, "In pursuit of luxury: global history and British consumer goods in the eighteenth century", en Past and Present, $182,2004,85-142$.

, "New consumers industries in eighteenth-century England:

Products, markets and metal goods in Birmingham and Sheffield”, en René Leboutte, ed., Proto-industrialisation. Recherches récentes et nouvelles perspectives, Ginebra, Droz, 1996, 211-236.

, "The genesis of 'useful knowledge", en History of Science, 45:2, 2007, pp.123-133.

, La era de las Manufacturas 1700-1820. Una nueva historia de la Revolución industrial británica, Barcelona, Crítica, 1987, 362.

BERGÈre, Marie-Claire, "On the historical origins of Chinese underdevelopment", en Theory and Society, 13, 1984, 327-337.

BERY, Albert, "The Limited Role of Rural Small-Scale Manufacturing for Late-comers: Some Hypotheses on the Colombian Experience", en Journal of Latin American Studies, 19:2, 1987, 295-322.

Braudel, Fernand, Civilisation matérielle, économie et capitalisme, t. I-III, París, Folio, 1979.

Bushnell, David, "Estructura social y espacio geográfico", en G. Carrera Damas, y Lombardi, John, coords., La crisis estructural de las sociedades implantadas. Historia General de América Latina, vol. v., París, unesco-Trotta, 2003, 107-132.

Butlin, R. A., "Early industrialization in Europe: concepts and problems", en Geographical Journal, 152: 1, 1986, 1-8.

CaIlly, Claude, "Contribution à la définition d'un mode de production proto-industriel”, en Histore et Mesure, 7-1/2, 1993, 19-40.

Carmagnani, Marcelo, "Demografía y sociedad: La estructura social de los centros mineros del norte de México, 1600-1720", en Historia y población en México. Lecturas de Historia Mexicana 9, México, El Colegio de México, 1994, 122-162. 
Carmona Badía, Xan, "Clases sociales, estructuras agrarias e industria rural doméstica en la Galicia del siglo XVIII”, en Revista de Historia Económica, 2:3, 1984, 35-50.

Chandavarkar, Rajnarayan, "Industrialization in India before 1947: Conventional Approaches and Alternative Perspectives", enModern Asian Studies, 19: 3, 1985, 623-668.

ChaO, King, "La production textile dans la Chine traditionnelle", en Annales ESC, 39:6, 1984, 957-976.

Chiaramonte, José Carlos, Formas de sociedad y economía en Hispanoamérica, México, Grijalbo-unam, 1984.

Cipolla, Carlo M., Historia económica de la población mundial, México, Grijalbo-conaculta, 1990.

Ciriacono, Salvatore, "Venise et la Vénétie dans la transition vers l'industrialisation. A propos des thèses de Franklin Mendels", en René Leboutte, ed., Proto-industrialisation. Recherches récentes et nouvelles perspectives, Ginebra, Droz, 1996, 291-320.

Contsworth, H. John, "The economics Cycle in Bourbon Central Mexico: A Critique of the Recaudación del Diezmo Líquido en pesos, by Ouweneel and Bijleveld. II", en The Hispanic American Historical Review, 69:3, 1989, 549-557.

Cochet, François y Géard Henry, Les Révolutions Industrielles: processus historique, développements économiques, París, Armand Colin, 1995.

Coleman, D. C., "Proto-industrialization: a concept too many", en The Economic History Review, 36: 3, 1983, 435-448.

Crosby Alfred W., Ecological imperialism. The biological expansion of Europe, 900-1900, Nueva York, Canto, 1999.

DE VRIES, Jan, "The industrial revolution and the industrious revolution", en Journal of Economic History, 54: 2, 1994, 249-270.

Desama, Claude, "Démographie et industrialisation: Le modèle verviétois (1800-1580)", en Revue du Nord, 63:248, 1981, 147155.

Dewerpe, Alain, "Genèse proto-industrielle d'une région développée: l'Italie septentrionale”, en Annales, Économie-Sociétés-Civilisations, 39:6, 1984, 896-914.

, L'Industrie aux Champs, essai sur la protoindustrialisation en 
Italie du Nord (1800-1880), París, Roma, Collection de l'École Française de Rome-Palais Farnèse, 1985.

Deyon, Pierre, "L'enjeu des discussions autour du concept de 'proto-industrialisation", en Revue du Nord, 61:240, 1979, 9-15.

, "Fécondité et limites du modèle protoindustriel: permier bilan", en Annales, Économies-Sociétés-Civilisations, 39:6, 1984, 868-881.

Deyon, Pierre y Mendels Frankuin, "La proto-industrialisation: Théorie et réalité", en Revue du Nord, 63:248, 1981, 11-16.

Dовв, Maurice, Estudios sobre el desarrollo del capitalismo, México, Siglo XXI, 1988.

Domar, Evsey y Mark Machina, "On the profitability of Russian Serfdom", en The Journal of Economic History, 44:4, 1984, 919955.

Duplessis, Robert S., "Sheilagh Ogilvie, State corporatism and proto industry: the Wurttember black forest 1580-1797, New York, Cambridge University Press, 1997”, en Canadian Journal of History/Annales canadiennes d'histoire, 33, 1998, 290-291.

Feuerwerker, Albert, "Presidential address: questions about china's early modern economic history that I wish I could answer", en Journal of Asian Studies, 51:4, 1992, 757-769.

GonZÁLEZ EnCIso, Agustín, "La protoindustrialización en España”, en Revista de Historia Económica, 2:1, 1984, 11-44.

GraY, Jane, "Gender composition and household labour strategies in pre-Famine Ireland", en History of the Family, 11, 2006, 1-18.

Gullicson, Gay L., "Agriculture and cottage industry: redefining the cause of proto-industrialization", en Journal of Economic History, 43: 4, 1983, 831-850.

GutManN, Mayron, "War and industrial development in early modern Europe", en René Leboutte, ed., Proto-industrialisation. Recherches récentes et nouvelles perspectives, Ginebra, Droz, 1996, 153-180.

HendRICKx, Francois M. M., "Family, farm and factory: Labor and the family in the transition from protoindustry to factory in $19^{\text {th }}$ century Twente, The Netherlands", en History of the Family, 8:1, 2003, 45-69. 
, "From weavers to workers: demographic implications of an economic transformation in Twente (The Netherlands) in the nineteenth century", en Continuity and Change, 8:2, 1993, 321355.

Ho, Samuel, "Protoindustrialisation, protofabriques et désindustrialisation: une analyse économique", en Annales ESC, 39:6, 1984, 882-895.

Hobsвawm, Eric, Entorno a los orígenes de la Revolución Industrial, México, FCE, 1981.

Honenberg, Paul, "Urbanization and proto-industrialization. Reflections on an intellectual journey", en René Leboutte, coord., Proto-industrialisation. Recherches récentes et nouvelles perspectives, Ginebra, Droz, 1996, 9-28.

Houston, Rab y K. D. M. Snell, "Proto-Industrialization? Cottage Industry, Social Change, and Industrial Revolution", en The Historical Journal, 27:2, 1984, 473-462.

Howell, David L., "Proto-industrial origins of Japanese capitalism”, en Journal of Asian Studies, 51:2, 1992, 269-286.

Hubscher, Roland, "De la integración del campesinado en la sociedad global: la pluriactividad ¿un equilibrio o una desestabilización de la sociedad rural?", en Serie de Traducciones, núm. 1, Universidad Nacional del Mar de la Plata, 1996, 24.

Hudson, Pat y Steve KIng, "Two textile townships, c. 1660-1820: A comparative demographic analysis", en The Economic History Review, 53:4, 2000, 706-741.

InKsTER, Ian, Japanese industrialisation. Historical and cultural perspectives, Londres, Routledge, 2001.

JeAnnin, Pierre, "La protoindustrialisation: développement ou impasse?”, en Annales-ESC, 35:1, 1980, 52-65.

Kertzer, David, "Household History and Sociological Theory", en Annual Review of Sociology, 17, 1991, 155-179.

KING, Steven A., "The English proto-industrial family: old and new perspectives", en History of the Family, 8:1, 2003, 21-43.

Komlos, John H., "Poverty and industrialization at the end of the 'Phase-transition' in Czech Crown Lands", en Journal of Economic History, 43:1, 1983, 129-135. 
Koo, Hagan, "From farm to factory: proletarianization in Korea", en American Sociological Review, 55:5, 1990, 669-681.

Kriedte, Peter, Hans Medick y Jürgen Schlumbohm, "Proto-industrialization revisited: demography, social structure and modern domestic industry", en Continuity and Change, 8:2, 1993, 217-252.

, "Proto-industrialisation: Bilan et perspectives. Démographie, structure social et industrie à domicile moderne", en R. Leboutte, ed., Proto- industrialisation. Recherches récentes et nouvelles perspectives, Ginebra, Droz, 1996, 29-71.

, Industrialización antes de la industrialización, Barcelona, Crítica, 1986.

KRIEDTE, Peter, Peasants landlords and merchant capitalist, Londres, Berg Publishers, 1983.

LANDES, David, L'Europe technicienne ou le Prométhée libéré: Révolution technique et libre essor industriel en Europe occidentale de 1750 à nos jours, París, Gallimard, 1975.

Leвоutte, René, "Adaptation, reconverions, mutations. Le rôle de la proto-industrialisation dans la genèse du bassin industriel Liégeois", en René Leboutte, ed., Proto-industrialisation. Recherches récentes et nouvelles perspectives, Ginebra, Droz, 1996, 263-290.

LeE, John, "Trade and Economy in Preindustrial East Asia, c. 1500c. 1800: East Asia in the Age of Global Integration", The Journal of Asia Studies, 58:1, 1999, 2-26.

Levine, David, "Asymmetrical, non-linear population dynamics", en René Leboutte, ed., Proto-industrialisation. Recherches récentes et nouvelles perspectives, Ginebra, Droz, 1996, 93-105.

LibBy, Douglas C., "Reconsidering Textile Production in Late Colonial Brazil: New Evidence from Minas Gerais", en Latin American Research Review, 1:1, 1997, 88-108.

LyNCH, John, "Los factores estructurales de la crisis: La crisis del orden colonial", en G. Carrera Damas y J. Lombardi, coord., La crisis estructural de las sociedades implantadas. Historia General de América Latina, vol. v, París, unesco, Trotta, 2003, 31-54.

MaGer, Wolfgang, "Proto-industrialization and proto-industry: the uses and drawbacks of two concepts", en Continuity and Change, $8: 2,1993,181-215$. 
Maitte, Corinne, "Incertitudes et bricolages. L'industrie textile à Prato aux 18ème et 19ème siècle", en Annales-HSS, 6, 1997, 1275-1303.

Manrique, Nelson, "Las sociedades originarias en el ámbito de la formulación inicial de los proyectos nacionales como culminación de los procesos de continuidad y ruptura”, en G. Carrera y J. Lombardi, coords., La crisis estructural de las sociedades implantadas. Historia General de América Latina, vol. v, París, UNESCO, Trotta, 2003, 351-364.

MarX, Karl, Le Capital, Livre I, París, Puf, 1993.

Maynes, Mary Jo, "Unthinking teleologies", en Social Science History, 30:1, 2006, 1-13.

McClain, James L., "Bonshogatsu. Festivals and State Power in Kanazawa”, en Monumenta Nipponica, 47:2, 1992, 163-202.

McCorriston, Joy, "The fiber revolution: textile extensification, alienation, and social stratification in ancient Mesopotamia”, en Current Anthropology, 38:4, 1997, 517-549.

McInthos, Terence, "Schwabish Hall, 1650-1750: Urban Social and Economic Life in Southwest Germany After the Thirty Years' War", en Journal of Economic History, 51:2, 1991, 462464.

Melton, Edgar, "Proto-industrialization, Serf Agriculture and Agrarian Social Structure: Two Estates in Nineteenth-Century Russia", en Past and Present, 115, 1987, 69-106.

Mendels, Franklin, "Le temps de l'industrie et le temps de l'agriculture. Logique d'un analyse régionale de la protro-industrialization", en Revue du Nord, 63:248, 1981, 21-33.

"Proto-industrialization: The first phase of industrialization process", en The Journal of Economic History, 32:1, 1972, 241-261.

, "Niveau des salaires et âge au mariage en Flandre, XVIIeXVIIIe siècles", en Annales, Économies-Sociétés-Civilisations, 39:6, 1984, 939-956.

"Social mobility and phase of industrialization", en Journal of Interdisciplinary History, 17:2, 1976, 193-216.

Mentz von, Brígida, Trabajo, sujeción y libertad en el centro de la 
Nueva España. Esclavos, aprendices, campesinos y operarios manufactureros, siglos XVI a XVIII, México, Ciesas, Porrúa, 1999.

Miño Grijalva, Manuel, “¿Proto-industria colonial?”, Historia Mexicana, núm. 4, vol. 38, abril-junio, 1989, 793-818

, "La circulación de mercancías: una referencia al caso textil latinoamericano (1750-1810)", en A. Ouweneel y C. Torales, coords., Empresarios, indios y Estado. Perfil de la economía mexicana (siglo XVIII), México, Universidad Iberoamericana, 1992, 75-96.

, La manufactura colonial. La constitución técnica del obraje, México, El Colegio de México, 1993.

, Obrajes y tejedores de Nueva España, 1700-1810, México, El Colegio de México, 1998.

NaKano, Meg, “Book Review: Japan's Proto-industrial Elite”, en Reviews in the Humanities and Social Sciences, junio, 2000, 1-3.

O'BrIEn, Patrick, "Do we have typology for the study of European industrialization in the 19th century?", en The Journal of European Economic History, 15:2, 1986, 291-333.

,"Path Dependency or Why Britain Became an Industrialized and Urbanized Economy Long before France", en The Economic History Review, 49:2, 1996, 213-249.

Ogilvie, Sheilagh, "Proto-industrialisation in Europe", en Continuity and Change, 8:2, 1993, 159-179.

Ogilvie, Sheilagh y Jeremy Edwards, "Women and the 'Second Serfdom': Evidence from Early Modern Bohemia”, en The Journal of Economic History, 60:4, 2000, 961-994.

Ouweneel, Arij, Shadows over Anáhuac. An ecological interpretation of crisis and development in central Mexico, 1730-1800, Albuquerque, University of New Mexico Press, 1996.

, "Don Claudio Pesero y la administración de la hacienda de Xaltipan (Tlaxcala), 1734-1737", en A. Ouweneel, y C. Torales Pacheco, coords., Empresarios, indios y Estado. Perfil de la economía mexicana (siglo XVIII), México, Universidad Iberoamericana, 1992, 257-287.

"Growth, Stagnation, and Migration: An explorative Analysis of the Tributario Series of Anahuac (1720-1800)", en The Hispanic American Historical Review, 71:3, 1991, 531-577. 
"Raíces del chiaroscuro en México algunas consideraciones acerca de esta compilación”, en A. Ouweneel, y C. Torales Pacheco, coord., Empresarios, indios y Estado. Perfil de la economía mexicana (siglo XVIII), México, Universidad Iberoamericana, 1992a, 13-33.

"The agrarian cycle as a catalyst of economic development in 18th century Central-Mexico. The arable estate, Indian village and proto-industrialization in Central highlands valleys", Ibero-Amerikanisches Archiv, 15:3, 1989a, 399-417.

Ouweneel, Arij y Catrien C.J.H. Bijleveld "Comments on "The economic Cycle in Bourbon Central Mexico: A critique of the Recaudación del Diezmo Líquido en pesos”, en The Hispanic American Historical Review, 69:3, 1989, 549-557.

Perlin, Frank, "State Formation Reconsidered: Part Two", en Modern Asian Studies, 19:3, 1984, 415-480.

PFISTER, Ulrich, "Work Roles and Family Structure in Proto-Industrial Zurich", en Journal of Interdisciplinary History, 20:1, 1989, 83-105.

Pietschmann, Horst, "Agricultura e industria rural indígena en el México de la segunda mitad del siglo xvin", en A. Ouweneel y C. Torales Pacheco, coords., Empresarios, indios y Estado. Perfil de la economía mexicana (siglo XVIII), México, Universidad Iberoamericana, 1992, 115-138.

Reynolds, Lloyd G., "The Spread of Economic Growth to the Third World: 1850-1980", en Journal of Economic Literature, 21:3, 1983, 941-980.

Riojas, Carlos, "Guadalajara y sus grupos domésticos a principios del siglo XIx: una aproximación al enfoque proto-industrial", en Jahrbuch für Geschichte Lateinamerikas, vol. 46, 2009, 313-343. "El Verlagssystem y las estrategias empresariales", en Signos Históricos, núm. 22, julio-diciembre, 2009, 108-145.

, Las intransitables vias del desarrollo: el proceso de industrialización en Jalisco durante el siglo XIX, México, Universidad de Guadalajara, 2003.

, "Consideraciones metodológicas para el estudio del proceso de industrialización en el occidente de México durante el siglo 
XIX", en Reinhard Liehr, ed., Empresas y modernización en México desde las reformas borbónicas hasta el Porfiriato, Madrid, Frankfurt, Iberoamericana, Vervuert, 2006, 130-160.

Rudolph, Richard, "Agricultural structure and proto-industrialization in Russia: economic development with unfree labor", en Journal of Economic History, 45:1, 1985, 47-69.

, "Family Structure and Proto-industrialization in Russia", en The Journal of Economic History, 40:1, 1980, 111-118.

SAIto, Osamu, "Historical Demography: achievements and prospects", en Population Studies, 50:3, 1996, 537-553.

SMAIL, John, "Manufacturer or artisan? The relationship between economic and cultural change in the early stages of the eighteencentury industrialization", en Journal of Social History, 25:4, 1992, 791-814.

SoKoloff, Kenneth y David Dollar, "Agricultural seasonality and organization of manufacturing in Early industrial economies: The contrast between England and the United States", en The Journal of Economic History, 57:2, 1997, 288-321.

Solow, Robert M., La teoría del crecimiento, México, FCE, 1992.

Subrahmanyam, Sanjay, "Rural Industry and Commercial Agriculture in Late Seventeenth-Century South-Eastern India", en Past and Present, 126, 1990, 76-114.

TERrIER, Didier, Les deux âges de la proto-industrie. Les tisserands du Cambrésis et du Saint-Quentinois, 1730-1880, París, EEHss, 1996. Thomson, Guy P.C., Puebla de los Angeles. Industry and society in a Mexican City, 1700-1850, Boulder Colorado, Westwiew Press, 1989.

"Traditional and Modern manufacturing in Mexico, 1821-1850”, en R. Liehr, ed., América Latina en la época de Simón Bolivar: La formación de las economias nacionales y los intereses económicos europeos 1800-1850, Berlín, Colloquim, 1989a, 55-85.

"Continuity and Change in Mexican Manufacturing, 1800-1870", en J. Batou, ed., Between Development and Underdevelopment: The precocious attemps at industrialization of the Periphery, 1800-1870, Ginebra, Droz, 1991, 255-302. 
Tову, Ronald P., "Both a Borrower and Lender Be. From Village Moneylender to Rural Banker in the Tempo Era”, en Monumenta Nipponica, 46:4, 1991, 483-512.

TORras Elias, Jaume, "Especialización agrícola e industria rural en Cataluña en el siglo xvIII", en Revista de Historia Económica, 2:3, 1984, 113-127.

Tortolero Villaseñor, Alejandro, Notarios y agricultores. Crecimiento y atraso en el campo mexicano, 1780-1920. Propiedad, crédito, irrigación y conflictos sociales en el agro mexicano, México, Universidad Autónoma de México Iztapalapa, Siglo XXI, 2008.

Van Young, Eric, "The New Cultural History Comes to Old Mexico", en The Hispanic American History Review, 79: 2, 1999, 211 247.

VARDI, Liliana, "Imagining the harvest in early Modern Europe", The American Historical Review, 101:5, 1996, 1357-1397.

WeIL, François, "Capitalism and industrialization in New England, 1815-1845", en The Journal of American History, 84: 4, 1998, 1334-1354.

WIGEN, Karen, “The geographic imagination in early modern Japanese history: Retrospect and prospect", en Journal of Asian Studies, 51: 1, 1992, 3-29.

Wrigley, E.A., Gentes, ciudades y riqueza. La transformación de la sociedad tradicional, Barcelona, Crítica, 1992.

FeCHA DE RECEPCIÓN DEL ARTÍ́culo: 4 de marzo de 2011

FECHA DE RECEPCIÓN DE LA VERSIÓN FINAL: 31 de octubre de 2011 